\title{
Composite Geological Strength Index Approach with Application to Hydrothermal Vein Networks and Other Intrablock Structures in Complex Rockmasses
}

\author{
Jennifer J. Day (D) Mark S. Diederichs • D. Jean Hutchinson
}

Received: 2 July 2018/Accepted: 15 June 2019/Published online: 20 June 2019

(C) The Author(s) 2019

\begin{abstract}
Conventional rockmass characterization and analysis methods for geotechnical assessment in mining, civil tunnelling, and other excavations consider only the intact rock properties and the discrete fractures that are present and form blocks within rockmasses. As modern underground excavations go deeper and enter into more high stress environments with complex excavation geometries and associated stress paths, healed structures within initially intact rock blocks such as hydrothermal veins, veinlets and stockwork (termed intrablock structures) are having an increasing influence on rockmass behaviour and should be included in modern geotechnical engineering design. Field observations indicate the conventional Geological Strength Index (GSI) does not accurately estimate rockmass strength and behaviour of complex rockmasses. A modified GSI chart to
\end{abstract}

Present Address:

J. J. Day $(\bowtie)$

Department of Earth Sciences, University of New Brunswick, Fredericton, NB E3B 5A3, Canada

e-mail: jday@unb.ca

\section{J. J. Day · M. S. Diederichs · D. J. Hutchinson} Department of Geological Sciences and Geological Engineering, Queen's University, Kingston,

ON K7L 3N6, Canada

e-mail: diederim@queensu.ca

D. J. Hutchinson

e-mail: hutchinj@queensu.ca include intrablock structures and a new Composite Geological Strength Index (CGSI) methodology to combine multiple suites of rockmass structure using a weighted harmonic average are presented as tools to evaluate complex rockmasses that contain multiple suites of structure for application to geomechanical numerical models. CGSI is introduced and numerically validated using implicit and explicit finite element method numerical simulations of an underground excavation and a case study of field observations in an adit at the El Teniente mine in Chile. In both cases, the CGSI approach using the modified GSI chart results in an improved estimate of rockmass behaviour in implicit equivalent continuum numerical models when compared to a conventional GSI approach.

Keywords Rockmass characterization - Complex rockmasses · Healed intrablock structures · Geological Strength Index · Finite element method numerical models · Composite Geological Strength Index

\section{Introduction}

Modern civil and mining engineering excavations are increasingly being constructed in complex rockmasses and situated at deeper horizons that are subject to high in situ stresses. Examples of modern civil excavations include base tunnels for irrigation and vehicle transportation, caverns and tunnels for hydro power 
schemes, and deep geological repositories for the long-term storage of nuclear waste. Examples of modern mining excavations include giant block cave and sublevel cave mines for low grade disseminated orebodies such as hydrothermal porphyry deposits, which require hundreds of kilometers of excavation infrastructure and can be situated more than $1 \mathrm{~km}$ below ground surface.

Conventional rockmasses are comprised of intact rock blocks that are bounded by macro-scale fractures. Macro-scale fractures such as joints, bedding, and other fractures are termed by the authors as interblock structures. Complex rockmasses also contain mesoscale structures that behave as part of the intact rock in situ and in high quality, undisturbed, diamond drill core. These meso-scale structures such as hydrothermal veins, veinlets, and stockwork, and others, are termed by the authors as intrablock structures. The mechanical behaviour of intrablock structures is primarily controlled by infill mineralogy and geometrical properties such as thickness, persistence, and orientation. Intrablock structures can influence rockmass shear and tensile strength at excavation and larger scales and can control fragmentation after moderate disturbance and comminution.

While intact rock and interblock structures are routinely considered in geotechnical engineering design, intrablock structures were considered to be irrelevant to rockmass behaviour and stability in early to mid-twentieth century shallow excavation design. Therefore, the complexity of intrablock structures were not adequately or at all included in empirical rockmass classification systems, such as those discussed below. However, field observations in increasingly deep modern excavations, that are exposed to higher and more complex stress paths, have demonstrated that intrablock structures can have a significant influence on rockmass behaviour and should, therefore, be included in rockmass characterization for engineering design in these environments.

Conventional design practices typically do not consider the effect of intrablock structures. The purpose of this research is to address this issue by presenting a new methodology and tool to incorporate intrablock structures into rockmass characterization for continuum numerical modelling with implicit rockmass structures.

\subsection{Empirical Geotechnical Design Practices}

The majority of routine geotechnical design follows rockmass classification methodologies that have been empirically correlated to observed excavation behaviours to develop design charts that prescribe primary ground support, appropriate excavation dimensions, and other aspects related to excavation stability or controlled rockmass fragmentation. The Rock Mass Rating (RMR) (Bieniawski 1976, 1989), Modified Rock Mass Rating (MRMR) (Laubscher 1977, 1990; Laubscher and Jakubec 2001), and Norwegian Tunnelling Index, Q (Barton et al. 1974), remain some of the most popular rockmass classification systems around the world. These tools resulted in a significant improvement to reliable geotechnical design when faced with impractical field scale testing to assess rockmass strength parameters.

RMR and $Q$ are based on numerous tunnel and mine cases, while MRMR is an extension of RMR for specific application to mining projects. Most of the case histories on which MRMR is based are from caving operations. The routine use of these classification systems for a wide variety of projects continues to provide additional case studies and therefore continuing opportunity to refine parameter calibration. Especially for long-term projects that have already been operating for years or decades, consistent application of a classification system enables observational design and updates of excavation methods and support systems throughout the project. Nonetheless, problems may arise when changes in geology, stress, and other conditions occur along an excavation advance. Even for conventional rockmasses, the limited input parameters in classification systems result in output data that does not adequately capture the full impact of rockmass behaviour on excavation stability (van der Pouw Kraan 2014).

RMR and Q include little to no consideration of intrablock structure. The RMR system does not consider intrablock structure at all. The joint condition rating section of RMR ranges from "very rough surfaces, not continuous, no separation, unweathered wall rock" to "soft gouge $>5 \mathrm{~mm}$ thick or separation > 5 mm, continuous" (Bieniawski 1989). The Q system has a provision for "tightly healed" joint alteration which arithmetically improves the joint alteration rating (and overall Q value) from a joint with "surface staining only" by $33 \%$ (Barton et al. 
1974). There is no allowance for the wide range of strengths found in intrablock structures that are primarily controlled by various infill mineralogies. The MRMR system (Laubscher and Jakubec 2001) has a vein adjustment factor that reduces the strength of the intact rock block by assessing the vein frequency (veins per meter) and infill hardness. This factor does not influence the joint condition rating. The Mohs hardness number (Mohs 1825) is used as an analogue to describe the strength of veins. The range of the Mohs hardness scale applied to MRMR is only $0.2-5$ because values greater than 5 (such as apatite and quartz) were regarded as insignificant by Laubscher and Jakubec (2001). Open fractures are assigned a factor of 1 , and the veins in MRMR are only able to weaken the host rock. The procedure developed by Laubscher and Jakubec (2001) involves multiplying the inverse of the Mohs hardness value by the vein frequency per meter, to arrive at a fraction of the initial intact rock block strength. Although MRMR is the best empirical classification system for considering veins, it does not account for intrablock structures that strengthen the rockmass and the geometrical and strength parameters are limited. Furthermore, MRMR shares the most significant limitation with RMR and $\mathrm{Q}$, where the final result is a single rank value that cannot be directly used as an input to constitutive models for geomechanical material properties in numerical models.

\subsection{Numerical Geotechnical Design Practices}

The advancement of numerical modelling in geomechanics has driven significant research and development of numerical design software and modelling procedures. These powerful tools have reduced some reliance on analytical and empirical design solutions, in favour of techniques that are customizable for individual projects with complex geological conditions, excavation geometries, and associated stress conditions. A numerical approach therefore has the potential to provide the most accurate representation of a rockmass for geotechnical design. A technological limitation of numerical models is computational capacity, where models of rockmasses with multiple suites of structure have a scale restriction. An engineering limitation of numerical design today in complex rockmasses is the limited detail of geotechnical information that is available for data input. Many site investigation programs are designed to collect geotechnical data through the lens of empirical rockmass classification system parameters, which are not directly linked to constitutive models that can be applied to numerical models.

After decades of relying on empirical classification systems to assess rockmass quality and ground support prescriptions, a rockmass characterization system that depends on direct geological field observations was created: the Geological Strength Index (GSI) (Hoek 1994; Hoek et al. 1995). The goal was to create an intuitive system for qualified and experienced geologists and geological engineers to assess rockmass strength in the field and then apply the data to the Hoek-Brown strength criterion in numerical analyses. GSI has evolved to be used in conjunction with the Generalized Hoek-Brown rock and rockmass shear strength criterion by modifying the failure envelope from intact rock to rockmass strength, where the parameter values can be directly used as numerical model inputs (Hoek and Brown 1997; Hoek et al. 2002).

Preliminary numerical modelling regularly begins with an equivalent continuum representation of a rockmass, where the strength behaviours of the intact rock and rockmass are represented by a single strength criterion, such as Generalized Hoek-Brown. The Generalized Hoek-Brown criterion is commonly used in rock mechanics, where the failure envelope for intact rock is defined by the unconfined compressive strength (UCS) and the Hoek-Brown material constant, $m_{i}$ (Hoek et al. 2002). The influence of geological rockmass structures on the relationship between intact rock strength and rockmass strength is accounted for in the Generalized Hoek-Brown criterion by GSI, which is used to modify the failure envelope of intact rock to account for geological structures in a rockmass strength profile (e.g. Hoek et al. 1995, 2002, 2013; Hoek and Brown 1997; Hoek and Marinos 2000). The partnership of the Generalized Hoek-Brown criterion and GSI is particularly useful for numerical modelling because geotechnical field observations of a rockmass are directly incorporated into the numerical geomechanical properties.

The Hoek-Brown strength criterion was originally developed to be a basic rockmass strength criterion suitable for general practical application to estimate intact rock and rockmass strength for underground excavation design (Hoek and Brown 1980, 1988). The 
otherwise lack of suitable strength criteria for rockmasses at the time of its creation resulted in widespread use of the Hoek-Brown criterion by geologists and geotechnical engineers. The Hoek-Brown criterion is fundamentally applicable only to isotropic rockmasses where the rockmass behaviour is dominated by interlocking blocks, shear failure, and rotation of blocks formed by intersecting structural features (e.g. Hoek and Brown 1997). In the context of numerical modelling with current computation abilities, sparse anisotropic rockmass features should be modelled explicitly while isotropic rockmass structures are modelled implicitly as an equivalent continuum material.

\subsection{Quantifications of GSI}

Multiple researchers have developed quantified modifications to GSI, including Sonmez and Ulusay (1999), Cai et al. (2004), and Hoek et al. (2013), in response to challenges of subjectivity faced by practitioners with different levels of experience using the qualitative GSI system. These quantifications provide more objective definitions of GSI inputs using a numerical basis to improve communication between practitioners. Sonmez and Ulusay (1999) proposed the structure rating (SR) based on volumetric joint count (joints $/ \mathrm{m}^{3}$ ) and surface condition rating (SCR), estimated from discontinuity characteristics such as roughness, weathering, and infilling. This quantification was tested for validity using case histories of slope instabilities in Turkey. Cai et al. (2004) proposed a quantification of structure based on the mean discontinuity spacing $(\mathrm{S})$ or by the mean block volume $\left(\mathrm{V}_{\mathrm{b}}\right)$ and a quantification of surface condition similar to the joint condition factor ( $\mathrm{J}_{\mathrm{c}}$ coefficient) used by Palmstrøm (1996) in the RMi classification system. Where there are at least three joint sets, the mean block volume $\left(\mathrm{V}_{\mathrm{b}}\right)$ can be calculated using the joint spacing $\left(\mathrm{S}_{\mathrm{i}}\right)$ and the angles between joint sets $\left(\gamma_{\mathrm{i}}\right)$ (Palmstrøm 1996):

$V_{b}=\frac{S_{1} S_{2} S_{3}}{\sin \gamma_{1} \sin \gamma_{2} \sin \gamma_{3}}$

Compared to the variation in joint spacing, the effect of the joint intersection angle is minimal, so for practical purposes, the block volume $\left(\mathrm{V}_{\mathrm{b}}\right)$ can be approximated as (Cai et al. 2004):
$V_{b}=S_{1} S_{2} S_{3}$

For non-persistent or irregular joint sets, Cai et al. (2004) suggest direct measurement of representative blocks in the field is sufficient. Block volume $\left(\mathrm{V}_{\mathrm{b}}\right)$ as presented in the quantified GSI chart by Cai et al. (2004) ranges from $0.1 \mathrm{~cm}^{3}$ for the smallest foliated/ laminated/sheared structure, to $1 \mathrm{~cm}^{3}$ for the smallest disintegrated structure, to $1000 \mathrm{~cm}^{3}$ for the smallest very blocky structure, to $1 \mathrm{~m}^{3}$ for the largest blocky structure, and to $10 \mathrm{~m}^{3}$ for large massive structure.

The GSI chart was revisited in 2013 by the original author and colleagues to quantify the inputs and improve the uniformity for more effective implementation in numerical models when coupled with the Generalized Hoek-Brown strength criterion (Hoek et al. 2013). In this updated chart, GSI values can be determined quantitatively by summing the two linear scales that represent the discontinuity surface conditions (Scale A) and the interlocking of rock blocks defined by these intersecting discontinuities (Scale B). The ratings used to quantify the $A$ and $B$ scales must be from systems "that are familiar to engineering geologists and geotechnical engineers operating in the field" (Hoek et al. 2013). An example quantification of Scales A and B presented and tested by Hoek et al. (2013) use the "boringly reliable" (Hoek et al. 2013) Rock Quality Designation (RQD) by Deere et al. (1969) for rockmass structure, and the Joint Condition (JCond ${ }_{89}$ ) rating defined by Bieniawski (1989) for the discontinuity surface condition in the following relationship:

$G S I=1.5 \operatorname{JCond}_{89}+R Q D / 2$

The selection of appropriate quantities is dependent on the available field data for a given project and the experience of the involved personnel. This updated chart is designed to be flexible for user preferences in both the qualitative camp, where GSI is estimated from direct field observations of rockmasses, and the quantitative camp.

An important difference between the updated GSI chart by Hoek et al. (2013) and the version by Hoek and Marinos (2000), is the removal of the Massive and Laminated/Sheared bins of rockmass structure to be true to the fundamental assumption of the GSI system that rockmass deformation and strength are controlled by sliding and rotation of intact blocks of rock defined by intersecting discontinuities, and to account for 
micro-defects in the rock between laboratory testing and field scales (Hoek et al. 2013). Furthermore, it is assumed there are several sets of discontinuities and their spacing, relative to the excavation under consideration, results in a homogeneous and isotropic rockmass.

\subsection{Applications of GSI to Heterogeneous Rockmasses}

In areas where rockmasses are particularly heterogeneous with multiple layers or zones of materials that exhibit distinct mechanical properties, successful variations of GSI to address these types of rockmass structure have been developed on a case by case basis. Examples of heterogeneous rockmasses for which GSI has been modified include tectonically disturbed interbedded sediments (Marinos and Hoek 2001; Marinos 2019), transition zones between fresh granite to residual soils (Babendererde et al. 2004), ophiolite complexes with serpentinization (Marinos et al. 2006), and other variability arising from tectonism, weathering, and alteration (Marinos and Carter 2018). This demonstrates the flexibility of GSI and supports the introduction of modifications to GSI for application to hydrothermally altered rockmasses with stockwork veins and other healed rockmass structures that are presented in this study.

\subsection{Characterizing Healed Structures with GSI}

GSI (Hoek et al. 2013) and the Generalized HoekBrown rock strength criterion (Hoek et al. 2002) continue to be effective methods to assess conventional rockmasses comprised of intact rock (microscale structures at mineral grain boundaries) and fractures (macro-scale structures). However, unconventional and complex rockmasses that contain mesoscale intrablock structures, when coupled with deeper modern excavations, present another challenge. Mesoscale intrablock structures, such as hydrothermal veins, veinlets, stockwork, and lithified sediment disturbance features, exist within blocks bounded by macro-scale structures such as joints, bedding, and other fractures. Examples of hydrothermal vein types of intrablock structures in fragmented blocks (observed in an underground drift) and drill core are shown in Fig. 1.

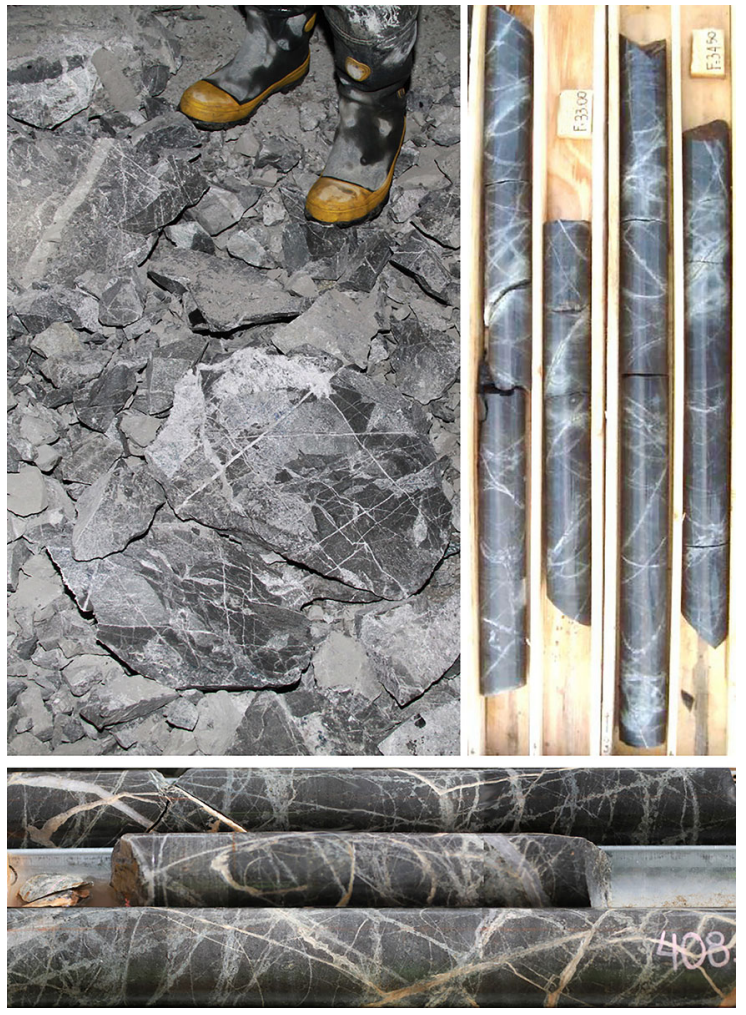

Fig. 1 Three examples of hydrothermal vein types of intrablock structures from Chile

Methods to estimate the strength of a complex rockmass that contains both interblock and intrablock structures are developed and presented in this work using finite element method (FEM) numerical tools. A new GSI chart is presented that includes intrablock structures and the new Composite GSI (CGSI) approach introduces a methodology to evaluate complex rockmasses with multiple suites of rockmass structure using the new chart. A numerical study is used to illustrate the improvements of CGSI in rockmass strength estimation from the conventional GSI approach. The CGSI method is also tested by FEM modelling of a case study of an adit at the El Teniente copper porphyry mine in Chile. In addition, the risks of a lack of consideration for or an erroneous assessment of intrablock structures are discussed. 


\section{Influence of Intrablock Structures on Rockmass Strength}

Most current design practices, based on either empirical or numerical approaches, do not consider the effect of intrablock structures on rockmass strength. It is commonly assumed that the rockmass strength is affected by intact strength and interblock structures such as joints and bedding; however, field evidence in deep, high stress environments has shown that hydrothermal intrablock structures such as veins, veinlets, and stockwork that exist in blocks of "intact" rock can also, when present, have an influence on rockmass strength and ultimately excavation stability.

Intrablock structures are important to consider in a variety of geological environments, such as hydrothermally altered volcanic settings and nodular sedimentary limestone. Hydrothermally altered rock contains a variety of associated minerals that are either disseminated in the intact rock or concentrated in multiple generations of veins, veinlets, and stockwork, or both. These minerals have a considerable range of stiffness and strength properties and can include quartz, pyrite, copper and other base metal sulphides, biotite, chlorite, gypsum, anhydrite, and clay minerals, among others (Sinclair 2007). Intrablock structures in argillaceous sedimentary limestone that are primarily composed of clay minerals and form around calcite-rich nodules develop from pressure dissolution during compaction (Choquette and James 1990) or intense bioturbation during deposition in a sheltered marine environment, which allows the bioturbated material to remain undisturbed during lithification (Johnson et al. 1992). The amount of clay minerals and their composition in nodular intrablock structures influence their geomechanical stiffness and strength properties (Day et al. 2017a, b).

Intrablock structures have a significant influence on rockmass shear and tensile strength in high stress environments. A distinguishing feature of intrablock structures is they can remain intact in good quality drill core (Fig. 1). In a rockmass under disturbance at the excavation scale, intrablock structures can control the ultimate fragmentation block size (Fig. 1 left). The influence of intrablock structures on rockmass strength depends on the thickness, persistence, orientation, and mineralization of each suite of intrablock structure.

The Mohs hardness scale for minerals (Mohs 1825; Tabor 1954) correlates hardness to the mechanical behaviour of infill mineralogies of intrablock structures. A common strengthening mineral that can appear welded to the wall rock is quartz (Fig. 2a-c). Other strengthening minerals include sulphides like pyrite and chalcopyrite (Fig. 2d-f) and strengthening quartz can also be interlaced with sulphide minerals (Fig. 2e). As mineral hardness decreases to minerals such as anhydrite, gypsum (Fig. 2g-i), epidote (Fig. 2j), calcite (Fig. 2k), biotite, muscovite (including fine-grained sericite), and clay minerals (Fig. 21$\mathrm{m})$, there is a transition between effects of strengthening to weakening of the rockmass by the intrablock structure, where local variations in thickness, persistence, and orientation control the effect on the overall rockmass. The competence of the contact between the wall rock and infill mineralogy of intrablock structure is also an important factor in the overall strength. Weaker and friable infill minerals tend to have poor adhesion to the wall rock while stronger minerals can have an excellent, fused contact (see Fig. 2a-f vs. h$\mathrm{m})$. Furthermore, alteration halos in the wall rock near vein contacts can also affect geomechanical behaviour. It is important to recognize the weakening or strengthening effects and competency of various mineralogies of intrablock structures for effective excavation design and implementation of ground support.

\section{Accounting for Intrablock Structures Using GSI}

The conventional use of the GSI system dictates that when evaluating a typical rockmass, the overall average block size of the structure and joint condition are selected and represented by a single GSI value. A conventional and conservative approach to incorporate another set or suite of structure with significantly different characteristics would be to combine the poorest quality characteristics from each block size and joint condition ranking to give an overall GSI value for the rockmass.

The CGSI method provides an improved estimate of strength for rockmasses that contain multiple suites of structure. While also applicable to conventional rockmasses that contain only interblock structures, CGSI is particularly designed for complex rockmasses that contain multiple suites of interblock and intrablock structures in various combinations. Modifications to the quantified and linearized GSI chart for 

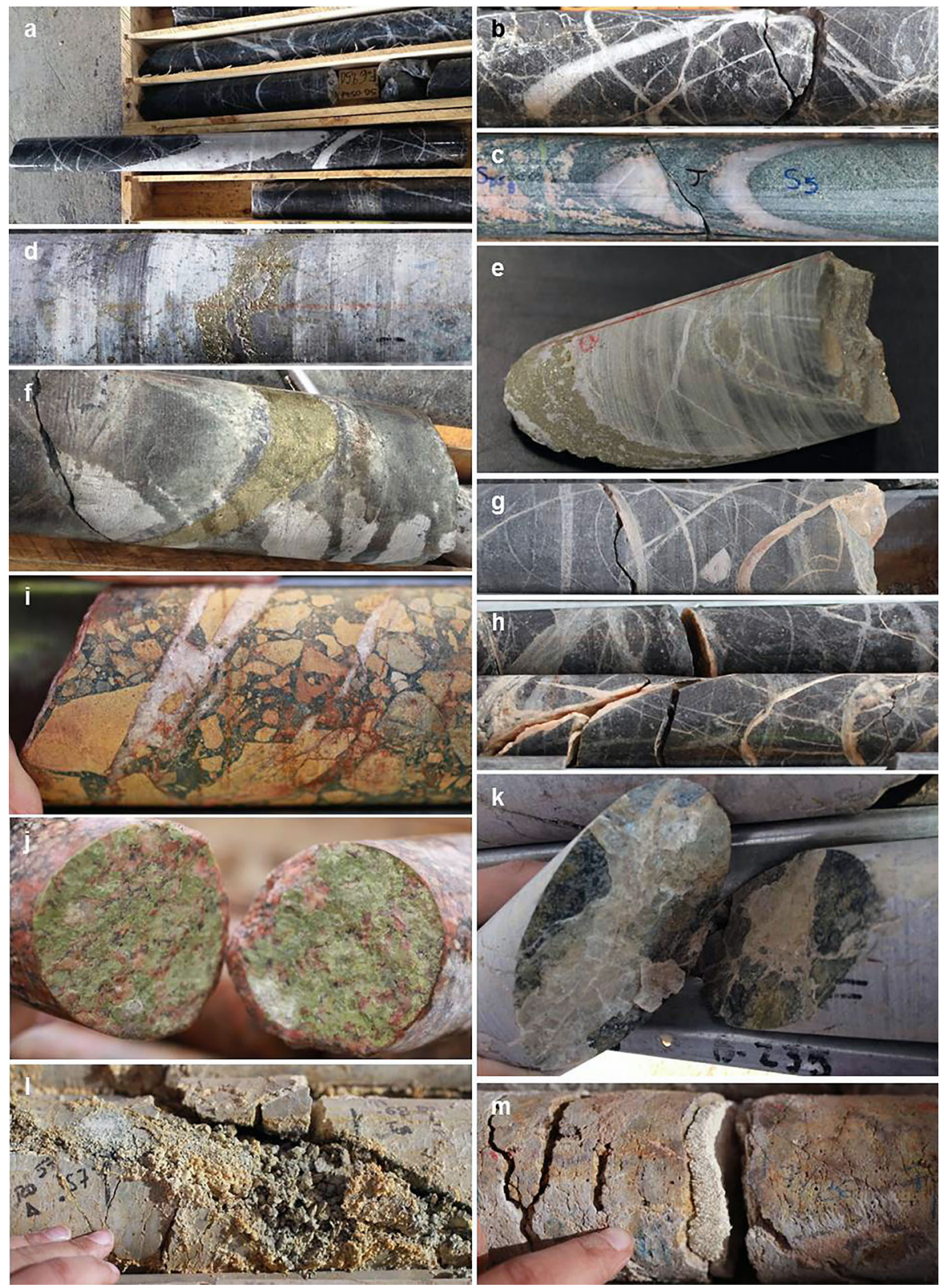

Fig. 2 Drill core from Chilean porphyry and Sudbury, Canada magmatic deposits showing various infill-wall rock contact qualities of intrablock structure; a-c strengthening welded quartz veins; $\mathbf{d}-\mathbf{f}$ sulphide veins (pyrite, chalcopyrite) with some

jointed rockmasses by Hoek et al. (2013) to include intrablock structures are presented in Fig. 3. A column is added to include strengthening intrablock structures with very good wall rock adhesion and higher hardness and strength. In addition, the descriptions of the existing discontinuity surface conditions are

quartz; $\mathbf{g}-\mathbf{i}$ healed and broken gypsum veins; $\mathbf{j}$ epidote vein that broke during drilling; $\mathbf{k}$ weak calcite vein that broke during drilling; l-m weak swelling clay infilling that has been altered and expanded by water application during core logging

modified to include a range of intrablock structures with variable competence and strength that overlaps with very good to fair quality joint surface conditions. For instance, hydrothermal quartz veins with a strong welded bond to the wall rock would be among the highest intrablock qualities while weakly bonded, 


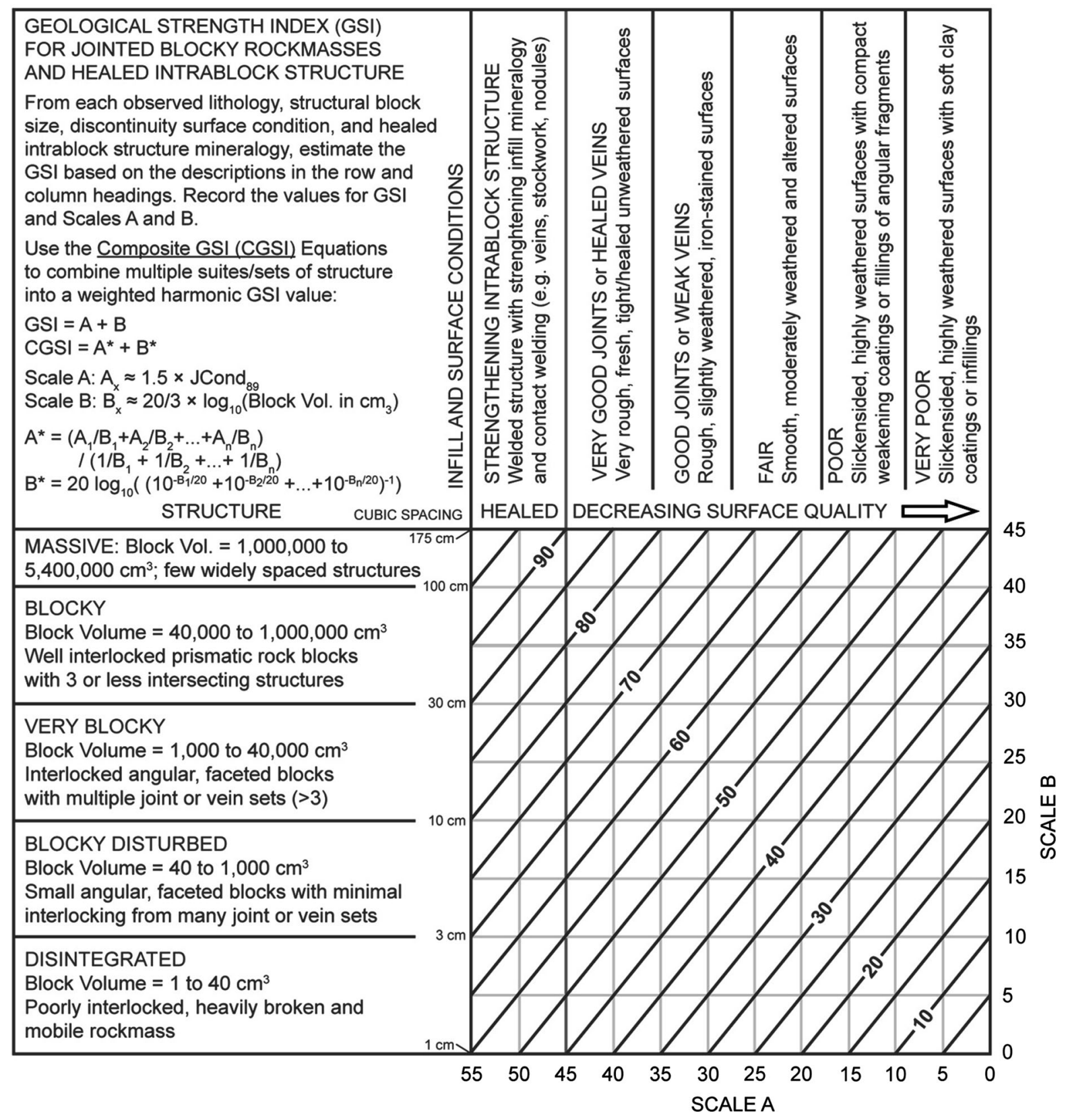

Fig. 3 New GSI chart for complex rockmasses that contain interblock and intrablock structures. The added column is used to describe the infill quality of strengthening intrablock structure

friable calcite or gypsum veins with poor adhesion would be among the lowest qualities.

Furthermore, a row for Massive structure geometry has been reinstated to incorporate widely spaced structures. In particular, this enables strengthening intrablock structures, which may counteract other and descriptions of other intrablock structure have been added to existing columns. A summary of equations to calculate the Composite GSI (CGSI) is also provided

micro-defects in the rock at the field scale, to result in GSI values between 85 and 100. It should be noted that this chart can still be used for common jointed blocky rockmasses considered in conventional GSI applications, which contain only interblock structures, with guidelines discussed by Hoek et al. (2013). 
The GSI quantification by Hoek et al. (2013) proposed general scales for structure geometry (Scale A) and condition (Scale B) such that GSI is equal to their sum (see Eq. 4). Values for Scales A and B that describe the rockmass structure can come from either direct field observations using the GSI descriptions for block size and discontinuity condition, scaled quantities from alternative geotechnical classification or characterization systems, or both. A modified version of the Joint Condition rating $\left(\mathrm{JCond}_{89}\right.$ ) from the 1989 version of the Rock Mass Rating classification system by Bieniawski (1989) is presented here that includes intrablock structures as an alternative means to calculate values for Scale A (Eq. 5). Similar to the column addition and other modifications to the GSI chart for intrablock structures, the modifications to JCond $_{89}$ include an added column and modified descriptions in existing columns for intrablock structures (see Table 1). Alternative quantified inputs used here for Scale B are based on the GSI quantification by Cai et al. (2004) using logarithmic considerations of rock block volume (Eq. 6).

$G S I=A_{x}+B_{x}$

$A_{x} \approx 1.5 \times \operatorname{JCond}_{89}$

$B_{x} \approx 20 / 3 \times \log _{10}\left(\mathrm{~V}_{\mathrm{b}}\right.$ in $\left.\mathrm{cm}^{3}\right)$

To calculate CGSI for a rockmass that contains multiple, distinct suites of rockmass structure, weighted composite values for Scale A and Scale B of all suites present are calculated using Eqs. 7 and 8 . $\mathrm{A}^{*}$ and $\mathrm{B}^{*}$ are therefore equivalent blended parameters for the composite rockmass.

$A^{*}=\frac{\left(A_{1} / B_{1}\right)+\left(A_{2} / B_{2}\right)+\cdots+\left(A_{n} / B_{n}\right)}{\left(1 / B_{1}\right)+\left(1 / B_{2}\right)+\cdots+\left(1 / B_{n}\right)}$
$B^{*}=20 \log _{10}\left(\left(10^{-B_{1} / 20}+10^{-B_{2} / 20}+\cdots+10^{-B_{n} / 20}\right)^{-1}\right)$

where $A_{1}$ and $B_{1}$ apply to the first suite of structure (e.g. joints), $A_{2}$ and $B_{2}$ apply to the second suite of structure (e.g. intrablock structure), and so on. CGSI is then defined by Eq. 9 .

$C G S I=A^{*}+B^{*}$

\section{Numerical Validation of Composite GSI}

A process using FEM numerical models is used to compare and quantify the differences between models of an excavation with explicit rockmass structure to two corresponding implicit equivalent continuum models where the rockmass structure is represented by GSI and CGSI, respectively. Total displacement measurements at the top, right, bottom, and left of the excavation boundary, and moving $9 \mathrm{~m}$ into the rockmass vertically and horizontally with query points spaced $0.091 \mathrm{~m}$, are used to calibrate discontinuity normal and shear stiffness values and compare the elastic model behaviour. Depth of plastic yield from the excavation boundary, measured at $45^{\circ}$ intervals around the excavation boundary, is used to calibrate discontinuity peak and residual strength properties and compare the elasto-plastic model behaviour. The explicit model is ultimately compared to the calibrated, implicit models to evaluate the better fit between CGSI and a conventional, conservative GSI approach.

The complex rockmass considered in this validation exercise contains one suite of interblock structure and one suite of intrablock structure. The rockmass responses around an excavation in separate explicit models with each suite of structure are calibrated to the corresponding behaviour in implicit models that represent each suite of structure. The calibrated explicit rockmass structures are combined into a full explicit model that contains both suites of structure. Finally, the rockmass behaviour of the full explicit model is compared to two implicit models of the full rockmass represented by the (i) GSI and (ii) CGSI approaches. This validation procedure is illustrated in Fig. 4.

The two suites of rockmass structure used in this study are (i) three sets of joints with similar surface conditions (interblock structure) and (ii) a stockwork network of healed but weakening hydrothermal anhydrite veins (intrablock structure). The characteristics of each suite of structure are defined using the GSI chart shown in Fig. 3 and are listed in Table 2. Each suite of structure has been assigned its own GSI value using the CGSI philosophy to first assess each suite individually, as if the rockmass contained only that suite. The GSI value for the full rockmass with both suites of structure was selected as the worst case conventional approach (i.e. using the minimum values 


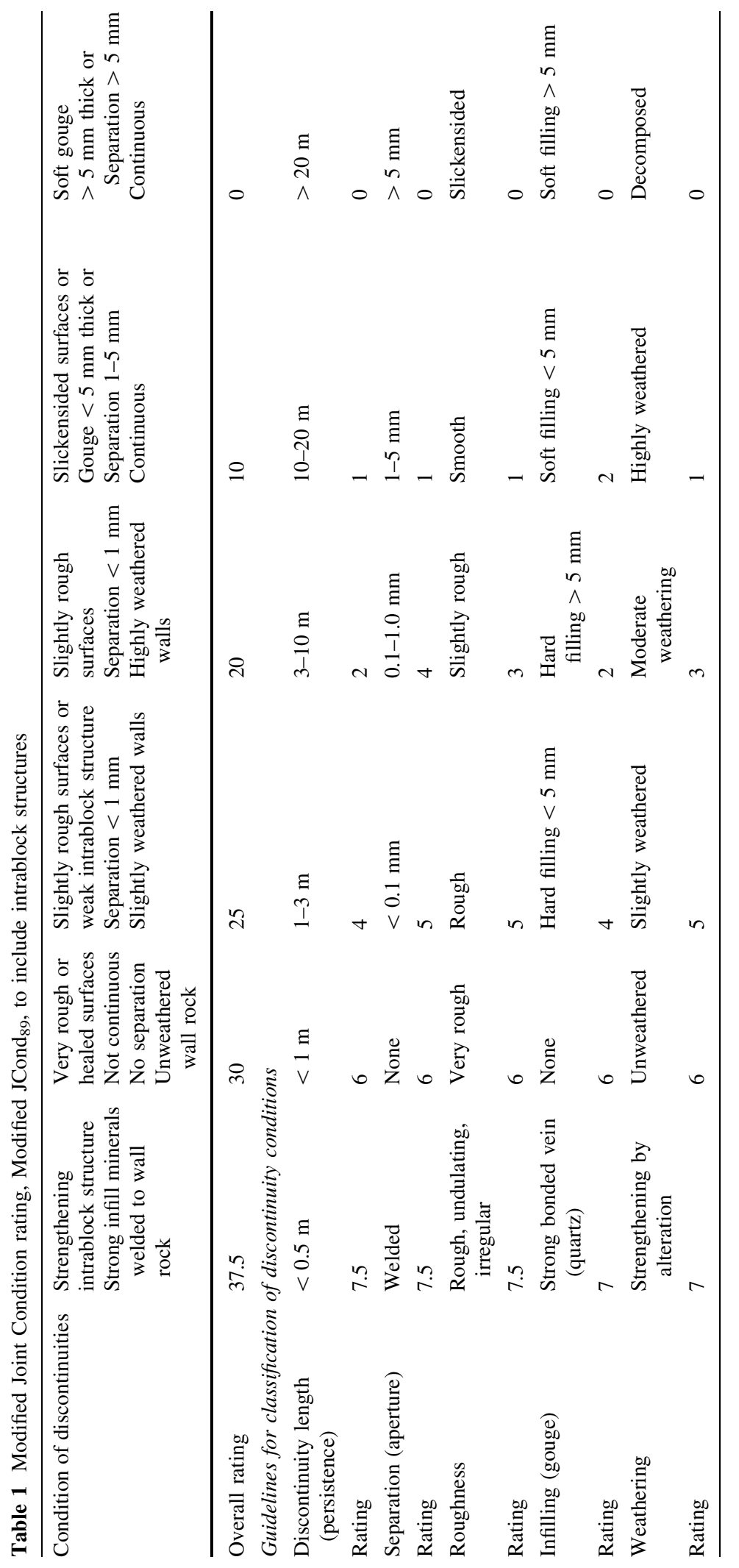




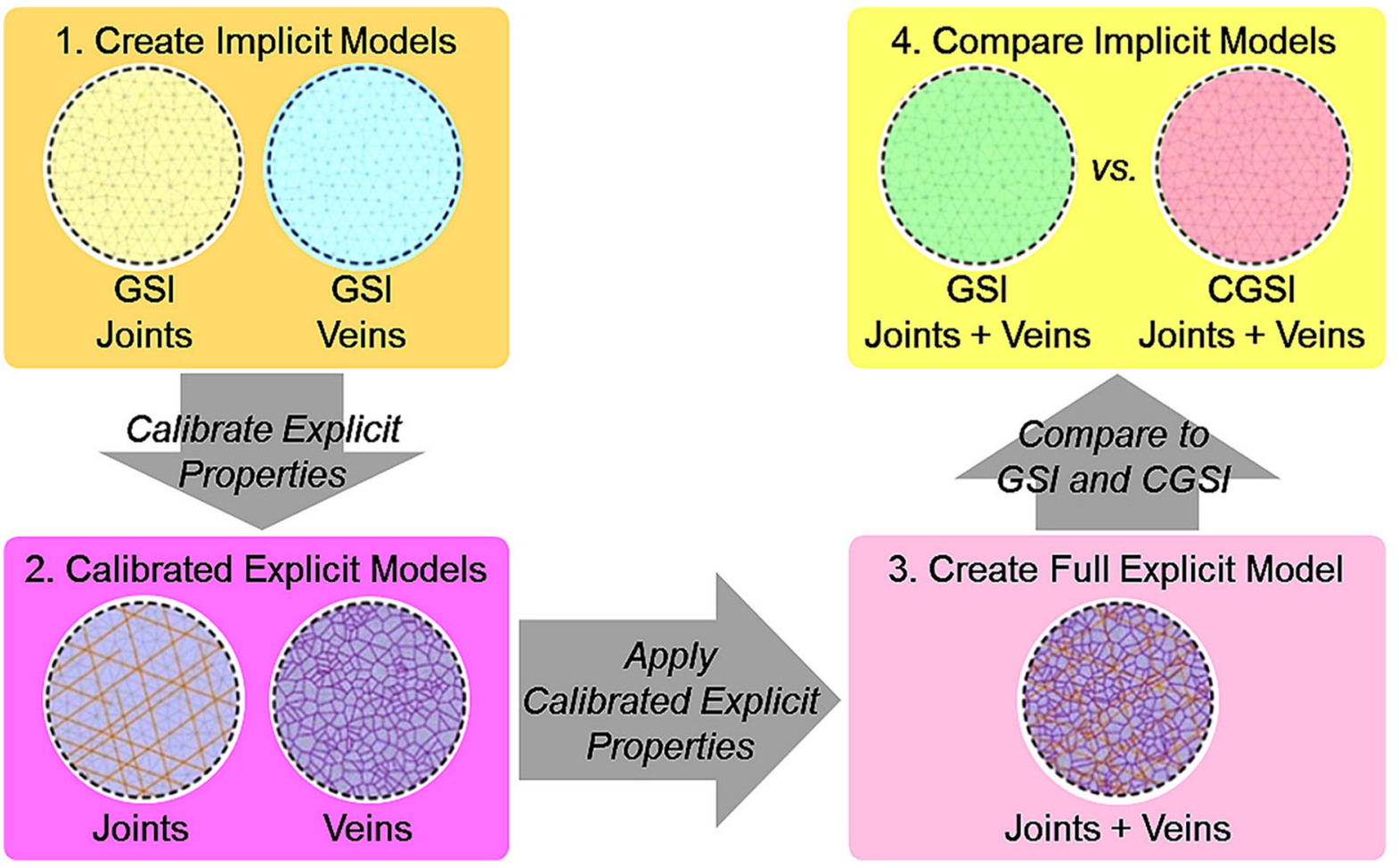

Fig. 4 Illustrative summary of FEM model comparison of conventional GSI and CGSI

Table 2 Geometry of rockmass structure in terms of GSI parameters

\begin{tabular}{llll}
\hline & Interblock: joints & Intrablock: anhydrite veins & Full rockmass \\
\hline Condition bin & "Fair" & $\begin{array}{c}\text { Border of "Strengthening Intrablock } \\
\text { Structure" and "Healed Veins" }\end{array}$ & - \\
Scale A & 25 & 45 & - \\
Structure bin & "Blocky" $(\sim 50 \mathrm{~cm}$ spacing $)$ & "Very Blocky" $\sim 20 \mathrm{~cm}$ spacing $)$ & - \\
Scale B & 35 & 25 & - \\
GSI & 60 & 70 & 50 \\
CGSI & - & - & 62 \\
\hline
\end{tabular}

for Scales A and B in Fig. 3) while the CGSI value for the overall rockmass was determined using Eqs. 4-9.

CGSI is designed to provide an improved estimate of rockmass strength for complex rockmasses. Field observations of other cases of excavations through complex rockmasses with interblock and healed intrablock structures indicate the conventional GSI approach underestimates their rockmass strength. This validation exercise compares models that contain individual explicit rockmass structures, which have each been calibrated to their implicit counterparts, to implicit models that represent the rockmass as a whole. Therefore, a real case study with observed or measured rockmass strain is not necessary for this comparison between the implicit models with minimal computational demand to the comprehensive explicit models.

\subsection{Numerical Model Setup}

This comparison between the GSI and CGSI approaches is conducted using FEM models of a 

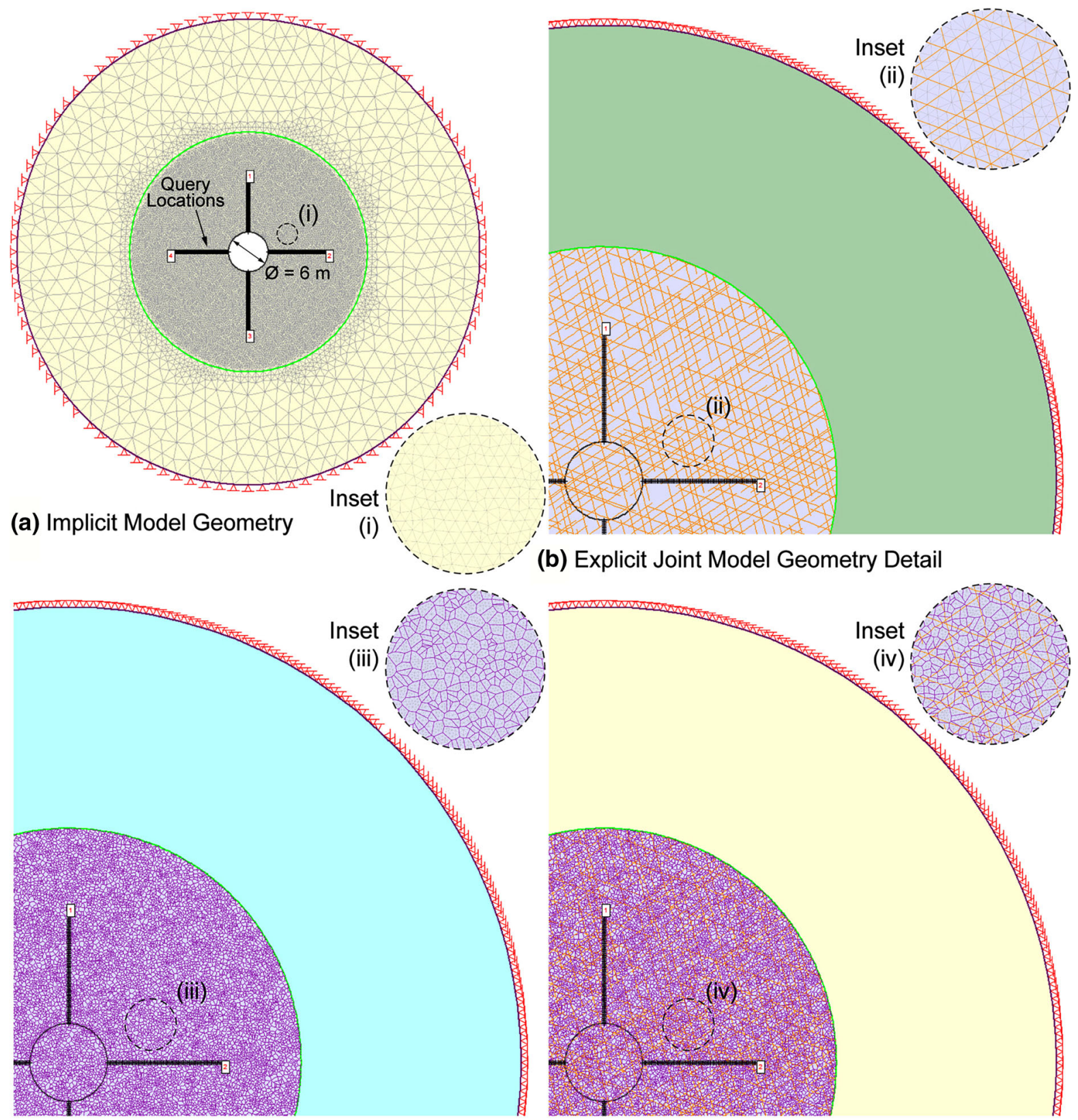

\section{(c) Explicit Vein Model Geometry Detail}

Fig. 5 Finite-element [RS2 by RocScience (2015)] model geometries of the circular $6 \mathrm{~m}$-diameter excavation showing: a full model of implicit rockmass structure with mesh, external boundaries, and the four query measurement lines; $\mathbf{b}$ excavation with explicit interblock (joint) geometry; c excavation with explicit intrablock (vein) geometry; $\mathbf{d}$ excavation with explicit

$6 \mathrm{~m}$-diameter circular excavation going through the selected rockmass (Fig. 5a). The in situ stresses are approximated to a depth of $800 \mathrm{~m}$ with a $\mathrm{K}$ ratio of

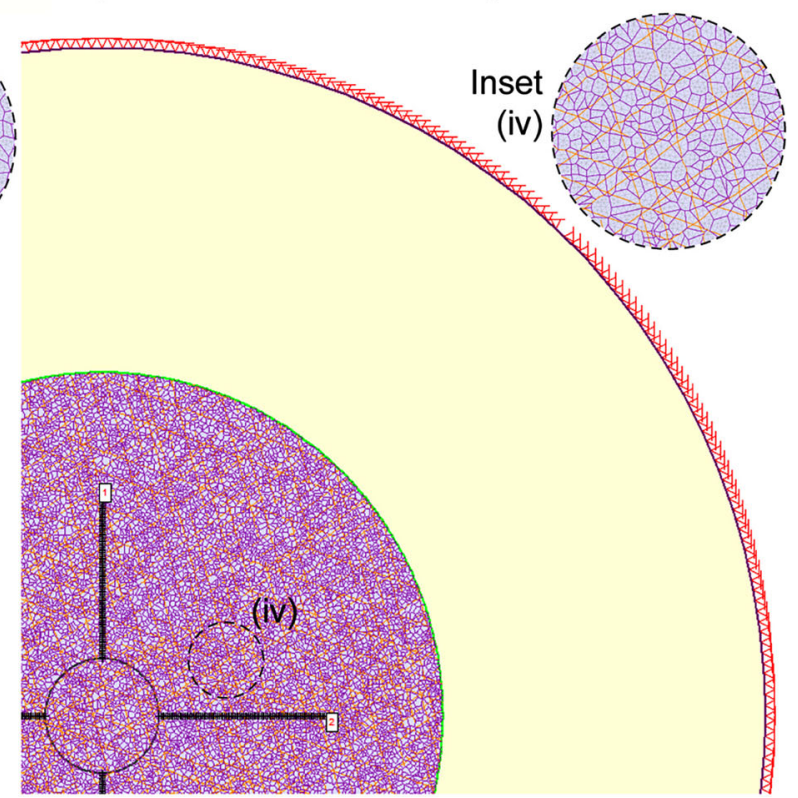

(d) Explicit Full Rockmass Model Geometry Detail

interblock (joint) and intrablock (vein) geometries (i.e. full rockmass); (i-iv) structure geometry and mesh detail; all models have a far field section of an equivalent continuum region for computational stability, and external boundaries have zero displacement (i.e. pinned) conditions

$\sim 2.1$, resulting in principal stresses of $45.1 \mathrm{MPa}$, 29.4 MPa and 21.6 MPa for $\sigma_{1}$ (horizontal and perpendicular to excavation axis), $\sigma_{2}$ (horizontal and 
Table 3 Intact rock properties used in the numerical validation study

\begin{tabular}{ll}
\hline Parameter & Elastic models \\
\hline Intact Young's modulus, $\mathrm{E}_{\mathrm{i}}(\mathrm{MPa})$ & 40,000 \\
Poisson's ratio, $v$ & 0.2 \\
Uniaxial compressive strength, UCS (MPa) & 110 \\
$m_{i}$ & 15 \\
$s$ & 1 \\
$a$ & 0.5 \\
GSI & 100 \\
\hline
\end{tabular}

parallel to excavation axis), and $\sigma_{3}$ (vertical), respectively. Intact rock properties in terms of the Generalized Hoek-Brown strength criterion (Hoek et al. 2002) are listed in Table 3.

\subsection{Elastic Calibration}

To obtain appropriate normal and shear stiffness properties for the explicit rockmass structure elements, the following calibration procedure was conducted using the 2D FEM software RS2 by RocScience (2015). The calibration procedure for the interblock joint structure suite is as follows (illustrated as Steps 1 and 2 in Fig. 4):

Step 1 An elastic model of the excavation with implicit joints (Fig. 5a) was created using a GSI value for the joint suite only (GSI $=60)$, as described in Table 2.

Step 2 An elastic model of the excavation with explicit joints (Fig. 5b) was created where the material properties represented the intact rock (see Table 3), and the initial (Trial 1) joint normal and shear stiffness properties were estimated based on published data (Read and Stacey 2009; Bandis et al. 1983; Goodman 1969). The total displacement measurements on the four query lines in the explicit elastic model were compared to those of the implicit elastic model to calibrate the stiffness properties. This was done by subtracting the total displacement measurements in the implicit model from those in the explicit model at each query point (there are 100 query points equally spaced along each query line, as illustrated in Fig. 5), and assessing the difference in total displacement values (Eq. 10). The implicit model is considered to be the baseline (zero values) to which deviations in the explicit models are compared.
Step 3 To reduce the deviations of total displacement from Trial 1, a trial and error process of joint stiffness property selection was conducted to determine a best fit explicit model, which is defined as having the smallest deviation of total displacement from the implicit baseline model. The total displacement results were compared graphically (Fig. 6) and quantitatively using the total displacement deviation, $\left(\delta_{d e v}\right)_{x=i}$, at the excavation boundary (Eq. 10, when $\mathrm{x}=0 \mathrm{~m})$, absolute mean deviation, $\left|\mu_{\delta \text { dev }}\right|$, of each total query line (0-9 m into rockmass) (Eq. 11), and the sample standard deviations, $\mathrm{SD}_{\delta}$, of each total query line (0-9 $\mathrm{m}$ into rockmass) (Eq. 12). The quantitative results are shown in Table 4. Mean values of the quantitative measurements around the excavation were calculated using all measurement locations (top, right, bottom, and left). The top three minimum mean values of each quantitative measurement were assigned rank values of 3 (minimum values highlighted in blue with bold and italicized numbers), 2 (highlighted in green with bold numbers), and 1 (highlighted in yellow with italicized numbers). The maximum value of sum of the rank weights represents the best fit explicit model with the overall minimum deviation of total displacements compared to the implicit model.

$$
\begin{aligned}
& \left(\delta_{\text {dev }}\right)_{x=i}=\left(\delta_{\text {explicit }}\right)_{x=i}-\left(\delta_{\text {implicit }}\right)_{x=i} \\
& \left|\mu_{\text {ddev }}\right|=\left|\frac{\left(\delta_{\text {dev }}\right)_{x=0 \mathrm{~m}}+\left(\delta_{\text {dev }}\right)_{x=0.091 \mathrm{~m}}+\cdots+\left(\delta_{\text {dev }}\right)_{(x=9 \mathrm{~m})}}{n}\right|, n=100
\end{aligned}
$$

$$
\begin{gathered}
S D_{\delta}=\sqrt{\frac{\sum\left(\left(\delta_{d e v}\right)_{x=i}-\mu_{\delta d e v}\right)^{2}}{n-1}} \\
i=0,0.091, \ldots 9 \mathrm{~m}, n=100
\end{gathered}
$$

Trial 8 was determined to be the best fit by both visual inspection in all directions around the excavation and the quantitative measurements described above, with joint normal stiffness $\left(\mathrm{K}_{\mathrm{n}}\right)$ of $90,000 \mathrm{MPa} /$ $\mathrm{m}$ and shear stiffness $\left(\mathrm{K}_{\mathrm{s}}\right)$ of $45,000 \mathrm{MPa} / \mathrm{m}$.

The calibration procedure described above for the explicit model with joints only was also conducted to determine the best normal and shear stiffness properties for the explicit vein model (Fig. 5c). The best stiffness properties produce the elastic explicit model that has the minimum deviation of total displacements from the implicit model (GSI $=70$, as in Table 2). The 
Fig. 6 Elastic calibration results for joints from the excavation boundary to $9 \mathrm{~m}$ into the rockmass, highlighting the best fit (Trial 8) of the implicit model in blue. Total displacements in the explicit models are presented as deviations from the baseline implicit model and stiffness units are $\mathrm{GPa} / \mathrm{m}$

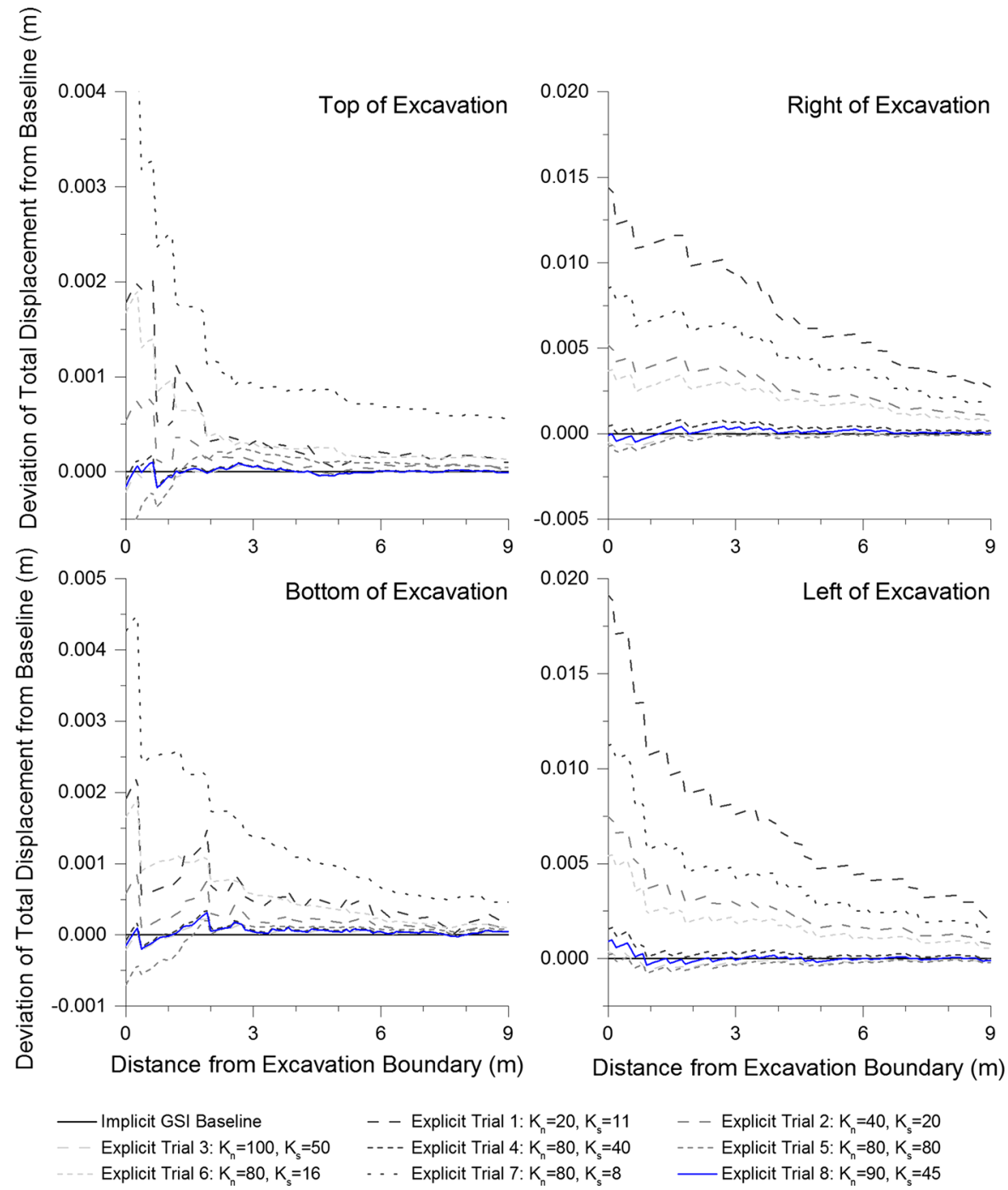

vein stiffness properties that were tested in the trial runs and the graphical calibration results are shown in Fig. 7. The graphical analysis and quantitative analysis (Table 7) both indicate that Trial 15 has the best fit vein stiffness properties, which are $K_{n-}$ $=600,000 \mathrm{MPa} / \mathrm{m}$ and $\mathrm{K}_{\mathrm{s}}=250,000 \mathrm{MPa} / \mathrm{m}$.

\subsection{Test of CGSI in Elastic Model}

Using the calibrated stiffness properties for the joint and vein structure suites that provide the best fit to implicit models with GSI values that correspond to each structure suite (as in Table 2), an explicit model containing both suites of structure can now be used to test the total displacement deviation of implicit models that use conventional GSI or CGSI. Two elastic implicit models of the excavation in the full rockmass, both joints and veins, were created using the GSI and CGSI values. An elastic explicit model of the excavation containing all rockmass structure, joints and veins (Fig. 5d), was created using the calibrated structural stiffness properties (Tables 4, 5). The 
Table 4 Quantitative analysis of elastic calibration of joint stiffness properties

\begin{tabular}{|c|c|c|c|c|c|c|c|c|c|c|c|c|c|c|c|c|c|}
\hline \multirow{2}{*}{$\begin{array}{l}\text { Joint } \\
\text { Model } \\
\text { Trial \# }\end{array}$} & \multirow{2}{*}{$\begin{array}{c}\text { Normal, } \\
\text { shear } \\
\text { stiffness } \\
(\mathrm{GPa} / \mathrm{m})\end{array}$} & \multicolumn{5}{|c|}{ Deviation of total disp. at excavation boundary } & \multicolumn{5}{|c|}{ Deviation of absolute value mean $0-9 \mathrm{~m}$ into rockmass } & \multicolumn{5}{|c|}{ Standard deviations 0-9 m into rockmass } & \multirow{2}{*}{$\begin{array}{c}\text { Sum of } \\
\text { mean } \\
\text { rank } \\
\text { weights }\end{array}$} \\
\hline & & Top & Right & Bottom & Left & Mean & Top & Right & Bottom & Left & Mean & Top & Right & Bottom & Left & Mean & \\
\hline 1 & 20,11 & 1.78E-3 & 1.44E-2 & $1.91 \mathrm{E}-3$ & $1.91 \mathrm{E}-2$ & $9.31 \mathrm{E}-3$ & 4.06E-4 & $7.25 \mathrm{E}-3$ & $5.34 \mathrm{E}-4$ & $6.95 \mathrm{E}-3$ & $3.78 \mathrm{E}-3$ & $4.99 \mathrm{E}-4$ & $3.22 \mathrm{E}-3$ & 4.18E-4 & $3.98 \mathrm{E}-3$ & 2.0294E-3 & 0 \\
\hline 2 & 40,20 & $5.42 \mathrm{E}-4$ & $5.19 \mathrm{E}-3$ & $5.83 \mathrm{E}-4$ & $7.48 \mathrm{E}-3$ & $3.45 \mathrm{E}-3$ & $1.41 \mathrm{E}-4$ & $2.72 \mathrm{E}-3$ & $2.23 \mathrm{E}-4$ & $2.57 \mathrm{E}-3$ & $1.41 \mathrm{E}-3$ & 1.83E-4 & 1.15E-3 & 1.67E-4 & $1.52 \mathrm{E}-3$ & $7.5452 \mathrm{E}-4$ & 0 \\
\hline 3 & 100,50 & $2.09 E-4$ & $5.26 E-4$ & 2.11E-4 & $3.74 \mathrm{E}-4$ & $3.30 \mathrm{E}-4$ & $7.64 \mathrm{E}-6$ & 1.13E-4 & $3.13 \mathrm{E}-5$ & $1.75 \mathrm{E}-4$ & $8.16 \mathrm{E}-5$ & $4.49 \mathrm{E}-5$ & $2.16 E-4$ & $7.35 \mathrm{E}-5$ & $1.81 \mathrm{E}-4$ & $1.2890 \mathrm{E}-4$ & 6 \\
\hline 4 & 80,40 & $8.32 E-5$ & 4.44E-4 & $7.89 E-5$ & $1.57 \mathrm{E}-3$ & $5.45 E-4$ & $1.54 E-5$ & $3.73 \mathrm{E}-4$ & $6.35 \mathrm{E}-5$ & $2.95 \mathrm{E}-4$ & 1.87E-4 & $4.52 E-5$ & $1.94 \mathrm{E}-4$ & $7.57 E-5$ & $3.23 \mathrm{E}-4$ & $1.5956 \mathrm{E}-4$ & 2 \\
\hline 5 & 80,80 & $6.91 \mathrm{E}-4$ & 7.37E-4 & $7.01 \mathrm{E}-4$ & $1.92 E-4$ & $5.80 \mathrm{E}-4$ & $5.24 \mathrm{E}-5$ & 2.37E-4 & $1.14 E-5$ & $2.60 E-4$ & $1.40 E-4$ & $1.81 \mathrm{E}-4$ & $2.56 \mathrm{E}-4$ & $1.99 \mathrm{E}-4$ & $1.80 \mathrm{E}-4$ & 2.0373E-4 & 1 \\
\hline 6 & 80,16 & $1.68 E-3$ & $3.69 \mathrm{E}-3$ & $1.66 \mathrm{E}-3$ & $5.42 \mathrm{E}-3$ & $3.11 \mathrm{E}-3$ & $3.89 \mathrm{E}-4$ & $2.07 \mathrm{E}-3$ & $5.20 \mathrm{E}-4$ & $1.83 \mathrm{E}-3$ & $1.20 \mathrm{E}-3$ & $4.08 \mathrm{E}-4$ & $8.47 \mathrm{E}-4$ & $4.14 \mathrm{E}-4$ & $1.12 \mathrm{E}-3$ & $6.9755 \mathrm{E}-4$ & 0 \\
\hline 7 & 80,8 & $4.38 \mathrm{E}-3$ & $8.53 \mathrm{E}-3$ & 4.27E-3 & $1.12 \mathrm{E}-2$ & $7.10 \mathrm{E}-3$ & $1.18 \mathrm{E}-3$ & 4.63E-3 & $1.32 \mathrm{E}-3$ & $4.09 \mathrm{E}-3$ & $2.80 \mathrm{E}-3$ & $9.37 \mathrm{E}-4$ & $1.95 \mathrm{E}-3$ & $9.31 \mathrm{E}-4$ & $2.37 \mathrm{E}-3$ & $1.5469 \mathrm{E}-3$ & 0 \\
\hline $8^{*}$ & 90,45 & $1.53 \mathrm{E}-4$ & $9.36 E-5$ & $1.52 \mathrm{E}-4$ & $9.08 E-4$ & $3.27 E-4$ & $2.42 E-6$ & $1.04 E-4$ & 4.56E-5 & $3.49 E-5$ & $4.68 \mathrm{E}-5$ & $4.20 E-5$ & $1.78 E-4$ & $7.33 E-5$ & $2.22 E-4$ & 1.2888E-4 & 9 \\
\hline \multicolumn{2}{|c|}{ Minimum values } & $8.32 E-5$ & $9.36 E-5$ & $7.89 E-5$ & $1.92 E-4$ & $3.27 E-4$ & $2.42 E-6$ & $1.04 E-4$ & $1.14 E-5$ & $3.49 E-5$ & $4.68 E-5$ & 4.20E-5 & $1.78 E-4$ & $7.33 E-5$ & $1.80 \mathrm{E}-4$ & $1.2888 E-4$ & \\
\hline
\end{tabular}

Fig. 7 Elastic calibration for veins from the excavation boundary to $9 \mathrm{~m}$ into the rockmass, highlighting the best fit (Trial 15) of the implicit model in red. Total displacements in the explicit models are presented as deviations from the baseline implicit model and stiffness units are $\mathrm{GPa} / \mathrm{m}$
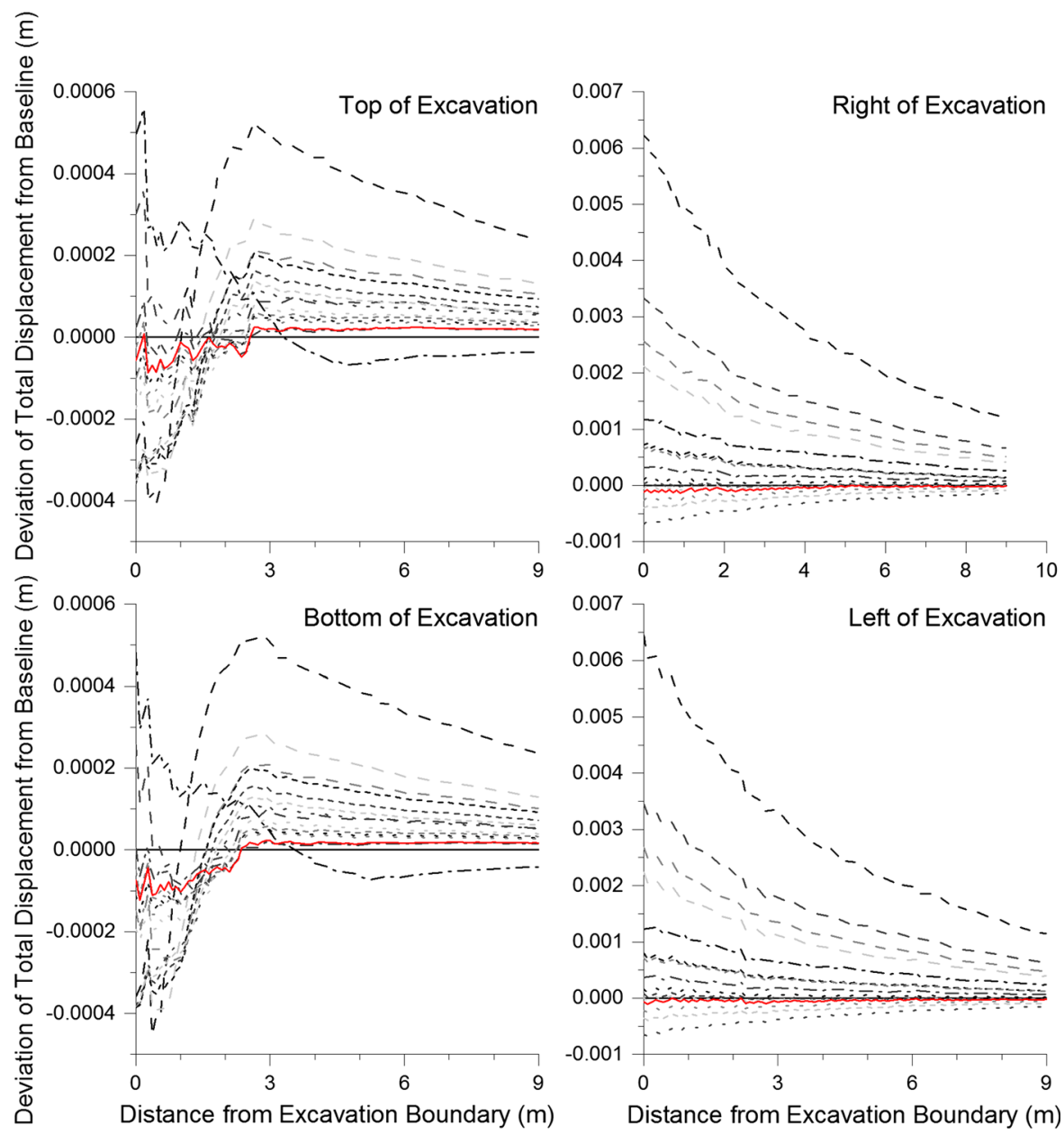

- Implicit GSI Baseline

- Explicit Trial 1: $K_{n}=100, K_{s}=100 \quad-$ Explicit Trial 2: $K_{n}=200, K_{s}=100 \quad-\quad$ Explicit Trial 3: $K_{n}=200, K_{s}=150$

Explicit Trial 4: $K_{n}=200, K_{s}=200 \quad$ - . - Explicit Trial 5: $K_{n}^{n}=300, K_{s}=300 \quad \ldots$ Explicit Trial 6: $K_{n}=400, K_{s}=400$

- . - Explicit Trial 7: $K_{n}=400, K_{s}=200 \quad \ldots$ Explicit Trial 8: $K_{n}=500, K_{s}=500 \quad \cdots$ Explicit Trial 9: $K_{n}=500, K_{s}=250$

‥ Explicit Trial 10: $\mathrm{K}_{n}=600, \mathrm{~K}_{\mathrm{s}}=600$ - . Explicit Trial 11: $\mathrm{K}_{\mathrm{n}}=600, \mathrm{~K}_{\mathrm{s}}=300$ - Explicit Trial 12: $\mathrm{K}_{\mathrm{n}}=500, \mathrm{~K}_{\mathrm{s}}=300$

- - Explicit Trial 13: $K_{n}=500, K_{s}=100-\cdots$ Explicit Trial 14: $K_{n}=500, K_{s}=200$ Explicit Trial 15: $K_{n}=600, K_{s}=250$ 
Table 5 Quantitative analysis of elastic calibration of vein stiffness properties

\begin{tabular}{|c|c|c|c|c|c|c|c|c|c|c|c|c|c|c|c|c|c|}
\hline \multirow{2}{*}{$\begin{array}{l}\text { Vein } \\
\text { Model } \\
\text { Trial \# }\end{array}$} & \multirow{2}{*}{$\begin{array}{l}\text { Normal, } \\
\text { shear } \\
\text { stiffness } \\
(\mathrm{GPa} / \mathrm{m})\end{array}$} & \multicolumn{5}{|c|}{ Deviation of total disp. at excavation boundary } & \multicolumn{5}{|c|}{ Deviation of absolute value mean $0-9 \mathrm{~m}$ into rockmass } & \multicolumn{5}{|c|}{ Standard deviations $0-9 \mathrm{~m}$ into rockmass } & \multirow{2}{*}{$\begin{array}{c}\begin{array}{c}\text { Sum of } \\
\text { mean rank } \\
\text { weights }\end{array} \\
\end{array}$} \\
\hline & & Top & Right & Bottom & Left & Mean & Top & Right & Bottom & Left & Mean & Top & Right & Bottom & Left & Mean & \\
\hline 1 & 100,100 & $2.62 \mathrm{E}-4$ & $6.23 \mathrm{E}-3$ & $3.58 \mathrm{E}-4$ & $6.45 \mathrm{E}-3$ & $3.32 \mathrm{E}-3$ & $2.82 \mathrm{E}-4$ & $2.89 \mathrm{E}-3$ & $2.84 \mathrm{E}-4$ & $2.89 \mathrm{E}-3$ & $1.58 \mathrm{E}-3$ & $2.25 \mathrm{E}-4$ & $1.38 \mathrm{E}-3$ & $2.28 \mathrm{E}-4$ & $1.45 \mathrm{E}-3$ & $8.21 \mathrm{E}-4$ & 0 \\
\hline 2 & 200,100 & $3.01 \mathrm{E}-4$ & $3.33 \mathrm{E}-3$ & $2.57 \mathrm{E}-4$ & $3.45 \mathrm{E}-3$ & 1.83E-3 & $7.65 \mathrm{E}-5$ & $1.58 \mathrm{E}-3$ & $5.16 \mathrm{E}-5$ & 1.58E-3 & $8.22 \mathrm{E}-4$ & $5.18 \mathrm{E}-5$ & $7.34 \mathrm{E}-4$ & $5.97 \mathrm{E}-5$ & $7.87 \mathrm{E}-4$ & $4.08 \mathrm{E}-4$ & 0 \\
\hline 3 & 200,150 & $1.00 \mathrm{E}-4$ & $2.56 \mathrm{E}-3$ & $1.50 \mathrm{E}-4$ & $2.68 \mathrm{E}-3$ & $1.37 \mathrm{E}-3$ & $9.57 \mathrm{E}-5$ & $1.20 \mathrm{E}-3$ & $8.57 \mathrm{E}-5$ & $1.21 \mathrm{E}-3$ & $6.47 \mathrm{E}-4$ & 1.17E-4 & $5.64 \mathrm{E}-4$ & $1.38 \mathrm{E}-4$ & $6.04 \mathrm{E}-4$ & $3.56 \mathrm{E}-4$ & 0 \\
\hline 4 & 200,200 & $3.29 \mathrm{E}-4$ & $2.12 \mathrm{E}-3$ & $3.84 \mathrm{E}-4$ & $2.23 E-3$ & $1.27 \mathrm{E}-3$ & $1.21 \mathrm{E}-4$ & $9.84 \mathrm{E}-4$ & 1.17E-4 & $9.85 \mathrm{E}-4$ & $5.51 \mathrm{E}-4$ & $1.72 \mathrm{E}-4$ & $4.65 \mathrm{E}-4$ & $1.86 \mathrm{E}-4$ & $4.97 \mathrm{E}-4$ & $3.30 \mathrm{E}-4$ & 0 \\
\hline 5 & 300,300 & $3.46 \mathrm{E}-4$ & $7.27 \mathrm{E}-4$ & $3.85 \mathrm{E}-4$ & $8.02 E-4$ & $5.65 \mathrm{E}-4$ & $6.65 \mathrm{E}-5$ & $3.34 \mathrm{E}-4$ & $6.28 \mathrm{E}-5$ & $3.35 \mathrm{E}-4$ & $2.00 \mathrm{E}-4$ & $1.50 \mathrm{E}-4$ & $1.58 \mathrm{E}-4$ & $1.62 \mathrm{E}-4$ & $1.79 \mathrm{E}-4$ & 1.62E-4 & 0 \\
\hline 6 & 400,400 & $3.53 \mathrm{E}-4$ & $2.46 \mathrm{E}-5$ & 3.83E-4 & $8.04 E-5$ & $2.10 \mathrm{E}-4$ & 3.97E-5 & $4.27 E-6$ & $3.68 \mathrm{E}-5$ & $4.98 E-6$ & $2.14 \mathrm{E}-5$ & $1.38 \mathrm{E}-4$ & $1.72 E-5$ & $1.47 \mathrm{E}-4$ & $2.54 E-5$ & $8.18 \mathrm{E}-5$ & 2 \\
\hline 7 & 400,200 & $2.51 \mathrm{E}-5$ & $6.49 \mathrm{E}-4$ & $5.02 \mathrm{E}-5$ & $7.11 \mathrm{E}-4$ & $3.59 \mathrm{E}-4$ & $2.26 \mathrm{E}-5$ & $3.14 \mathrm{E}-4$ & 1.06E-5 & $3.18 \mathrm{E}-4$ & $1.66 \mathrm{E}-4$ & $4.16 E-5$ & $1.40 \mathrm{E}-4$ & $5.77 E-5$ & $1.67 \mathrm{E}-4$ & $1.02 \mathrm{E}-4$ & 0 \\
\hline 8 & 500,500 & $3.57 \mathrm{E}-4$ & $4.00 \mathrm{E}-4$ & $3.81 \mathrm{E}-4$ & $3.56 \mathrm{E}-4$ & $3.73 E-4$ & $2.40 \mathrm{E}-5$ & $1.96 \mathrm{E}-4$ & $2.17 \mathrm{E}-5$ & 1.95E-4 & $1.09 \mathrm{E}-4$ & $1.29 \mathrm{E}-4$ & $9.22 \mathrm{E}-5$ & $1.36 \mathrm{E}-4$ & $7.99 \mathrm{E}-5$ & 1.09E-4 & 0 \\
\hline 9 & 500,250 & $9.09 \mathrm{E}-5$ & $1.05 E-4$ & 1.12E-4 & $1.54 \mathrm{E}-4$ & $1.15 E-4$ & 1.17E-5 & $5.51 \mathrm{E}-5$ & $2.29 \mathrm{E}-6$ & $5.86 \mathrm{E}-5$ & $3.19 \mathrm{E}-5$ & $4.79 \mathrm{E}-5$ & $2.56 \mathrm{E}-5$ & $6.14 \mathrm{E}-5$ & $4.49 \mathrm{E}-5$ & $4.49 \mathrm{E}-5$ & 3 \\
\hline 10 & 600,600 & $3.58 \mathrm{E}-4$ & $6.85 \mathrm{E}-4$ & $3.79 \mathrm{E}-4$ & $6.48 \mathrm{E}-4$ & $5.18 E-4$ & $1.37 \mathrm{E}-5$ & $3.30 \mathrm{E}-4$ & $1.18 \mathrm{E}-5$ & $3.30 \mathrm{E}-4$ & $1.71 \mathrm{E}-4$ & $1.23 E-4$ & $1.54 \mathrm{E}-4$ & $1.29 \mathrm{E}-4$ & 1.43E-4 & $1.37 \mathrm{E}-4$ & 0 \\
\hline 11 & 600,300 & $1.35 \mathrm{E}-4$ & $2.61 \mathrm{E}-4$ & $1.53 \mathrm{E}-4$ & $2.19 \mathrm{E}-4$ & $1.92 \mathrm{E}-4$ & $4.41 \mathrm{E}-6$ & $1.19 \mathrm{E}-4$ & 3.24E-6 & $1.16 \mathrm{E}-4$ & $6.06 \mathrm{E}-5$ & $5.30 \mathrm{E}-5$ & $6.35 \mathrm{E}-5$ & $6.44 \mathrm{E}-5$ & $4.57 \mathrm{E}-5$ & $5.66 \mathrm{E}-5$ & 0 \\
\hline 12 & 500,300 & $1.73 \mathrm{E}-4$ & $5.06 \mathrm{E}-5$ & 1.96E-4 & $2.33 E-6$ & $1.05 \mathrm{E}-4$ & $1.36 \mathrm{E}-5$ & $2.19 \mathrm{E}-5$ & $6.68 \mathrm{E}-6$ & $1.92 \mathrm{E}-5$ & $1.53 E-5$ & $7.34 \mathrm{E}-5$ & $2.26 \mathrm{E}-5$ & $8.53 \mathrm{E}-5$ & $1.79 E-5$ & $4.98 E-5$ & 6 \\
\hline 13 & 500,100 & $4.97 \mathrm{E}-4$ & $1.17 \mathrm{E}-3$ & $4.82 \mathrm{E}-4$ & $1.23 \mathrm{E}-3$ & $8.46 \mathrm{E}-4$ & 4.49E-5 & $5.84 \mathrm{E}-4$ & $2.57 \mathrm{E}-5$ & $5.92 \mathrm{E}-4$ & $3.12 \mathrm{E}-4$ & $1.42 \mathrm{E}-4$ & $2.55 \mathrm{E}-4$ & $1.14 \mathrm{E}-4$ & $2.94 \mathrm{E}-4$ & $2.01 \mathrm{E}-4$ & 0 \\
\hline 14 & 500,200 & $2.42 E-5$ & $3.19 \mathrm{E}-4$ & $4.80 E-6$ & $3.70 \mathrm{E}-4$ & $1.80 \mathrm{E}-4$ & $1.13 E-5$ & $1.61 \mathrm{E}-4$ & $1.44 \mathrm{E}-6$ & $1.66 \mathrm{E}-4$ & $8.50 \mathrm{E}-5$ & $2.04 E-5$ & $6.80 \mathrm{E}-5$ & $2.94 E-5$ & $9.37 \mathrm{E}-5$ & $5.29 \mathrm{E}-5$ & 0 \\
\hline $15^{*}$ & 600,250 & $5.64 E-5$ & $1.15 \mathrm{E}-4$ & $7.35 E-5$ & 7.14E-5 & $7.90 \mathrm{E}-5$ & $3.96 E-6$ & $4.60 E-5$ & $5.92 \mathrm{E}-6$ & $4.22 E-5$ & $2.45 E-5$ & $2.97 \mathrm{E}-5$ & $3.40 \mathrm{E}-5$ & $4.12 \mathrm{E}-5$ & $1.94 \mathrm{E}-5$ & $3.11 E-5$ & 7 \\
\hline \multicolumn{2}{|c|}{ Minimum values } & $2.42 E-5$ & $2.46 E-5$ & $4.80 E-6$ & $2.33 E-6$ & $7.90 E-5$ & $3.96 E-6$ & $4.27 E-6$ & $1.44 E-6$ & $4.98 E-6$ & $1.53 E-5$ & $2.04 E-5$ & $1.72 E-5$ & $2.94 E-5$ & $1.79 E-5$ & $3.11 E-5$ & \\
\hline
\end{tabular}

Fig. 8 Deviations of total displacements of implicit elastic equivalent continuum (GSI and CGSI) rockmass models from the baseline rockmass model with explicit structure
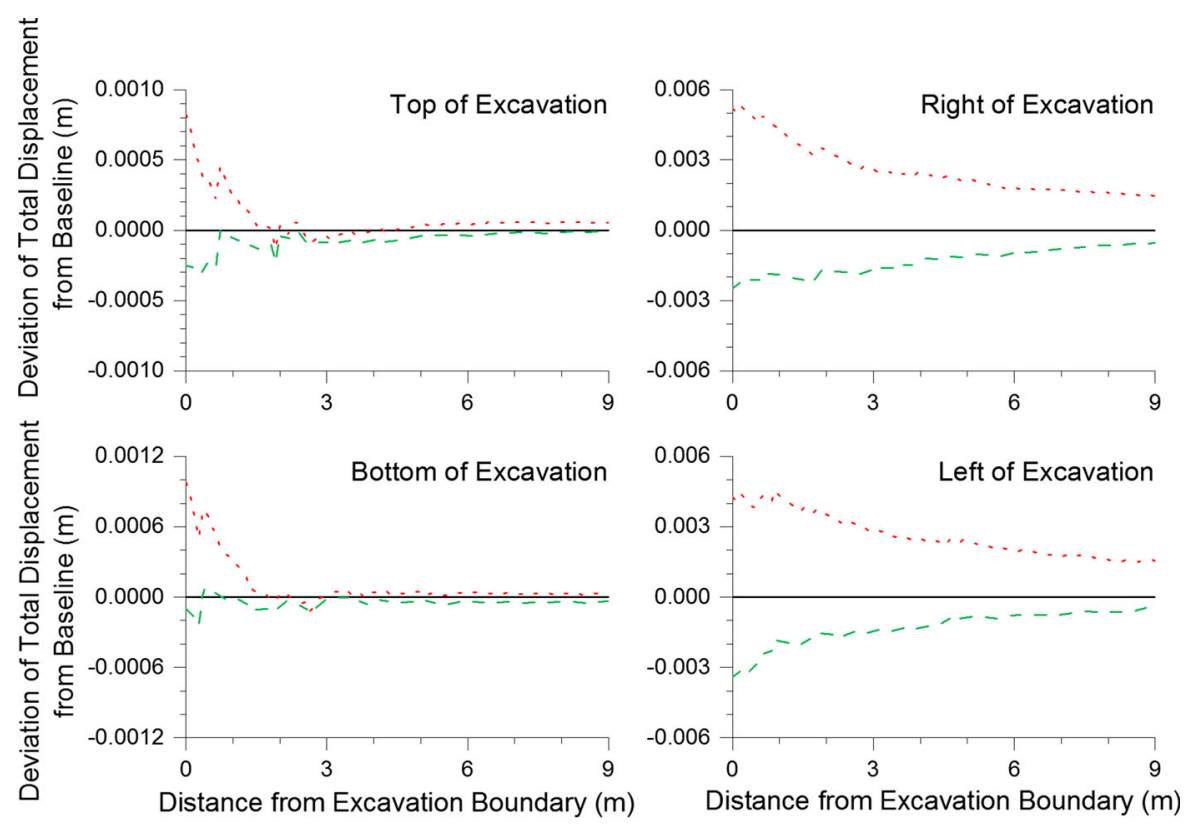

- Baseline Explicit Rockmass (Joints + Veins) - . - Implicit Rockmass GSI - - Implicit Rockmass CGSI explicit elastic model with both joints and veins was compared to the GSI and CGSI implicit models using total displacements measured along query lines at the top, right, bottom, and left of the excavation boundary, with query points spaced every $0.091 \mathrm{~m}$ and up to $9 \mathrm{~m}$ away from the excavation (Fig. 5a).
The explicit model containing both joints and veins (Fig. 5d) is the baseline model, where these total displacement measurements are subtracted from the total displacement measurements in each of the implicit models to consider the deviation of total displacements (Eq. 10) in the analysis. The best fit implicit model is considered to have the smaller 
Table 6 Quantitative analysis of elastic deviation of total displacements comparing GSI and CGSI implicit models to baseline explicit model with all rockmass structure

\begin{tabular}{|c|c|c|c|c|c|c|c|c|c|c|}
\hline \multirow{2}{*}{$\begin{array}{c}\text { Implicit } \\
\text { models }\end{array}$} & \multicolumn{4}{|c|}{$\begin{array}{c}\text { Deviation of absolute means of total disp. 0-9 m into } \\
\text { rockmass from explicit baseline }\end{array}$} & \multicolumn{4}{c|}{ Standard deviation of total displacements } \\
\cline { 2 - 11 } & Top & Right & Bottom & Left & Mean & Top & Right & Bottom & Left & Mean \\
\hline GSI & $7.7 \mathrm{E}-5$ & $2.6 \mathrm{E}-3$ & $9.7 \mathrm{E}-5$ & $2.6 \mathrm{E}-3$ & $1.3 \mathrm{E}-3$ & $1.6 \mathrm{E}-4$ & $1.1 \mathrm{E}-3$ & $2.0 \mathrm{E}-4$ & $8.9 \mathrm{E}-4$ & $5.8 \mathrm{E}-4$ \\
\hline $\mathrm{CGS}{ }^{*}$ & $6.9 \mathrm{E}-5$ & $1.3 \mathrm{E}-3$ & $4.8 \mathrm{E}-5$ & $1.3 \mathrm{E}-3$ & $6.8 \mathrm{E}-4$ & $6.8 \mathrm{E}-5$ & $5.4 \mathrm{E}-4$ & $4.3 \mathrm{E}-5$ & $7.1 \mathrm{E}-4$ & $3.4 \mathrm{E}-4$ \\
\hline $\begin{array}{c}\text { Minimum } \\
\text { values }\end{array}$ & $6.9 \mathrm{E}-5$ & $1.3 \mathrm{E}-3$ & $4.8 \mathrm{E}-5$ & $1.3 \mathrm{E}-3$ & $6.8 \mathrm{E}-4$ & $6.8 \mathrm{E}-5$ & $5.4 \mathrm{E}-4$ & $4.3 \mathrm{E}-5$ & $7.1 \mathrm{E}-4$ & $3.4 \mathrm{E}-4$ \\
\hline
\end{tabular}

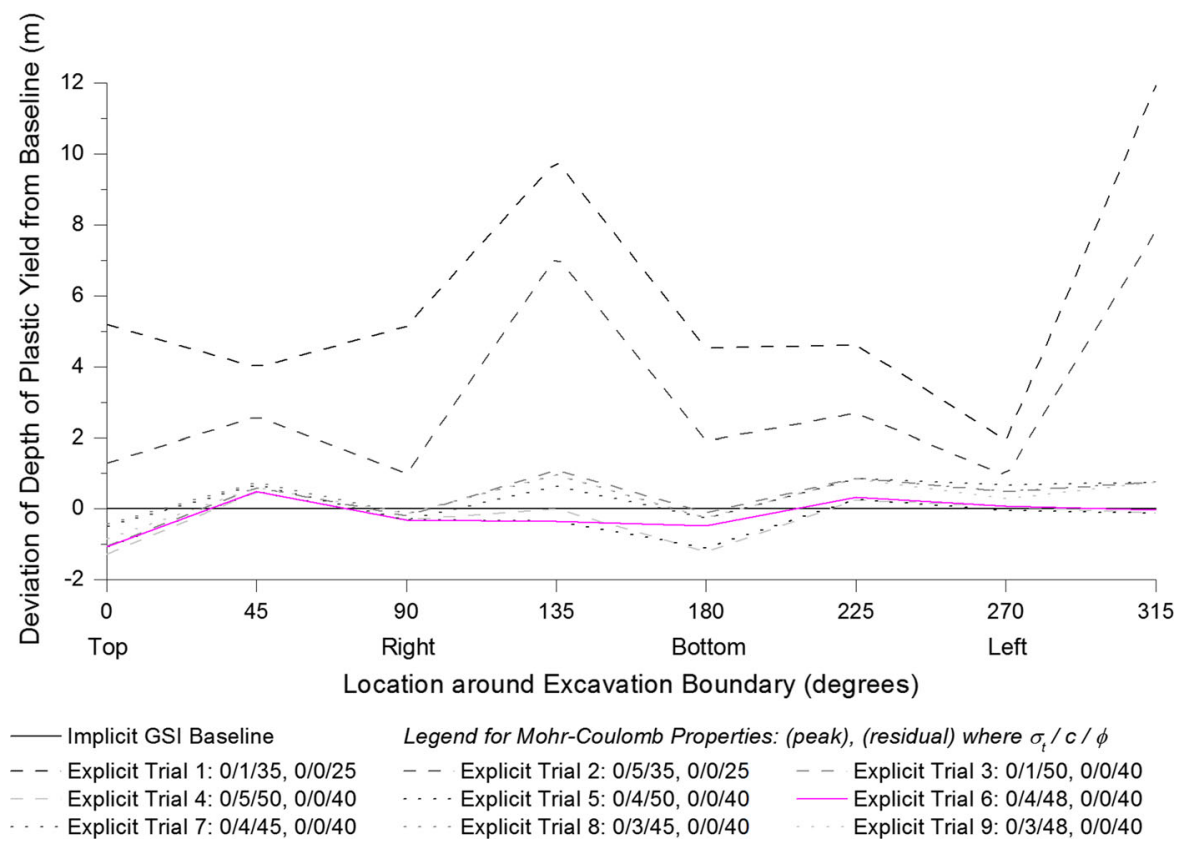

Fig. 9 Plastic model calibration for joint strength by measuring depth of plastic yield at $45^{\circ}$ intervals around the excavation, highlighting the best fit (Trial 6) of the implicit model in purple.

deviation of absolute means of total displacements (Eq. 11) and the smaller standard deviation of total displacements (Eq. 12) from the baseline explicit model. The graphical results are shown in Fig. 8 and quantitative results are shown in Table 6. This comparison illustrates that, at all measurement locations, the elastic CGSI model is an improved fit from the conventional GSI approach.

\subsection{Plastic Calibration}

For the elasto-plastic models comparing rockmass strength, a calibration procedure similar to that of the elastic models was conducted to obtain appropriate
Depths of plastic yield in the explicit models are presented as deviations from the baseline implicit model

strength properties for the explicit structure elements. The elasto-plastic models are calibrated and ultimately compared using measurements of the depth of plastic yield into the rockmass from the excavation boundary at 45 degree increments around the cross-section of the excavation. The depth of plastic yield measurements in each of the joint and vein implicit models were subtracted from those in the corresponding separate joint and vein explicit models. The separate implicit models are considered to be the baseline (zero values) to which deviations of depth of plastic yield (Eq. 13) in the corresponding explicit models are compared.

The depth of plastic yield results were compared graphically (Figs. 9, 10), and quantitatively using the 


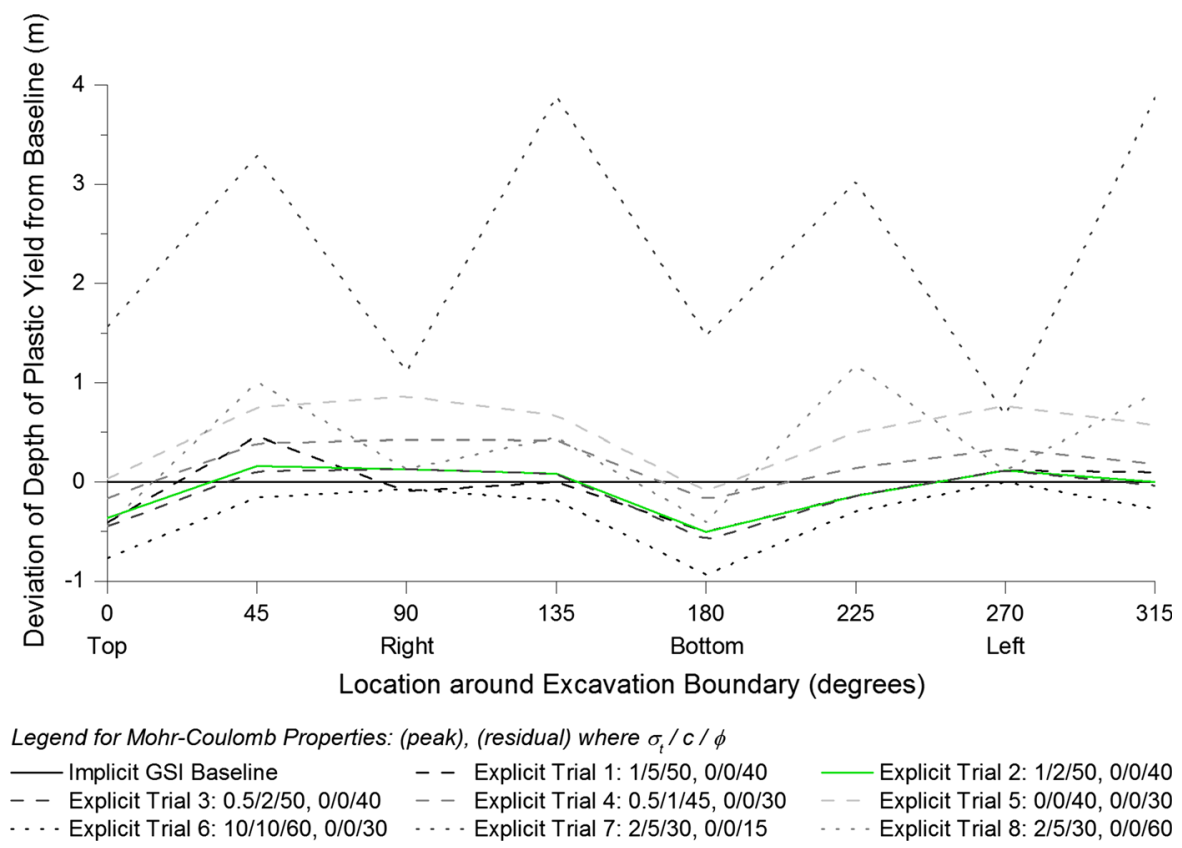

Fig. 10 Plastic model calibration for vein strength by measuring depth of plastic yield at $45^{\circ}$ intervals around the excavation, highlighting the best fit (Trial 2) of the implicit model in green.
Depths of plastic yield in the explicit models are presented as deviations from the baseline implicit model

softening Mohr-Coulomb parameters; however, some of the vein strength trials use the model of cohesion loss and friction mobilization that is typical of brittle materials (e.g. Martin 1997; Diederichs 2007).

The graphical observations and sum of rank weights from the quantitative analysis show that joint Trial 6 has the best fit joint strength properties, which are tensile strength, $\sigma_{\mathrm{t}}=0 \mathrm{MPa}$, cohesion, $\mathrm{c}=4 \mathrm{MPa}$, and friction angle, $\phi=48^{\circ}$ for peak strength and $\sigma_{\mathrm{t}}=0 \mathrm{MPa}, \mathrm{c}=0 \mathrm{MPa}$, and $\phi=40^{\circ}$ for residual strength. Vein Trial 2 has the best fit vein strength properties, which are $\sigma_{\mathrm{t}}=1 \mathrm{MPa}$, $\mathrm{c}=2 \mathrm{MPa}$, and $\phi=50^{\circ}$ for peak strength and $\sigma_{\mathrm{t}}=0 \mathrm{MPa}, \mathrm{c}=0 \mathrm{MPa}$, and $\phi=40^{\circ}$ for residual strength.

$$
\begin{aligned}
& \left(P_{\text {dev }}\right)_{x=i}=\left(P_{\text {explicit }}\right)_{x=i}-\left(P_{\text {implicit }}\right)_{x=i} \\
& \left|\mu_{\text {Pdev }}\right|=\left|\frac{\left(P_{\text {dev }}\right)_{\theta=0^{\circ}}+\left(P_{\text {dev }}\right)_{\theta=45^{\circ}}+\cdots+\left(P_{\text {dev }}\right)_{\theta=315^{\circ}}}{n}\right|, n
\end{aligned}
$$
properties are in terms of conventional strain-softening Mohr-Coulomb parameters. Most tested vein strength properties also use the conventional strain- 
Table 7 Quantitative analysis of plastic calibration of joint strength properties

\begin{tabular}{|c|c|c|c|c|c|}
\hline \multirow{2}{*}{$\begin{array}{c}\text { Joint Model } \\
\text { Trial \# } \\
\end{array}$} & \multicolumn{2}{|c|}{$\sigma_{\mathrm{t}}(\mathrm{MPa}) / \mathrm{c}(\mathrm{MPa}) / \phi\left(^{\circ}\right)$} & \multirow{2}{*}{$\begin{array}{c}\text { Absolute } \\
\text { mean }\end{array}$} & \multirow{2}{*}{$\begin{array}{l}\text { Standard } \\
\text { deviation }\end{array}$} & \multirow{2}{*}{$\begin{array}{c}\text { Sum of rank } \\
\text { Weights }\end{array}$} \\
\hline & Peak strength & Residual strength & & & \\
\hline 1 & $0 / 1 / 35$ & 0/0/25 & $5.9 \mathrm{E}+0$ & $3.3 \mathrm{E}+0$ & 0 \\
\hline 2 & $0 / 5 / 35$ & $0 / 0 / 25$ & $3.2 \mathrm{E}+0$ & $2.7 \mathrm{E}+0$ & 0 \\
\hline 3 & $0 / 1 / 50$ & 0/0/40 & $3.0 \mathrm{E}-1$ & $7.2 \mathrm{E}-1$ & 0 \\
\hline 4 & $0 / 5 / 50$ & 0/0/40 & $2.7 E-1$ & $6.5 \mathrm{E}-1$ & 1 \\
\hline 5 & $0 / 4 / 50$ & 0/0/40 & $2.9 \mathrm{E}-1$ & $5.7 \mathrm{E}-1$ & 0 \\
\hline $6^{*}$ & $0 / 4 / 48$ & 0/0/40 & $1.7 E-1$ & $4.9 E-1$ & 6 \\
\hline 7 & $0 / 4 / 45$ & $0 / 0 / 40$ & $3.1 \mathrm{E}-1$ & $5.6 E-1$ & 1 \\
\hline 8 & $0 / 3 / 45$ & 0/0/40 & 3.7E-1 & $5.6 \mathrm{E}-1$ & 2 \\
\hline 9 & $0 / 3 / 48$ & $0 / 0 / 40$ & $2.7 \mathrm{E}-1$ & $6.4 \mathrm{E}-1$ & 2 \\
\hline \multicolumn{3}{|c|}{ Minimum values } & $1.7 \mathrm{E}-1$ & $4.9 \mathrm{E}-1$ & \\
\hline
\end{tabular}

Table 8 Quantitative analysis of plastic calibration of vein strength properties

\begin{tabular}{|c|c|c|c|c|c|}
\hline \multirow{2}{*}{$\begin{array}{l}\text { Vein Model } \\
\text { Trial \# } \\
\end{array}$} & \multicolumn{2}{|c|}{$\sigma_{\mathrm{t}}(\mathrm{MPa}) / \mathrm{c}(\mathrm{MPa}) / \phi\left(^{\circ}\right)$} & \multirow{2}{*}{$\begin{array}{c}\text { Absolute } \\
\text { mean }\end{array}$} & \multirow{2}{*}{$\begin{array}{l}\text { Standard } \\
\text { deviation }\end{array}$} & \multirow{2}{*}{$\begin{array}{c}\text { Sum of rank } \\
\text { weights }\end{array}$} \\
\hline & Peak strength & Residual strength & & & \\
\hline 1 & $1 / 5 / 50$ & $0 / 0 / 40$ & $5.7 E-2$ & $3.1 \mathrm{E}-1$ & 3 \\
\hline $2^{*}$ & $1 / 2 / 50$ & 0/0/40 & $6.2 \mathrm{E}-2$ & $2.5 \mathrm{E}-1$ & 4 \\
\hline 3 & $0.5 / 2 / 50$ & 0/0/40 & $9.4 E-2$ & $2.8 E-1$ & 2 \\
\hline 4 & $0.5 / 1 / 45$ & 0/0/30 & $2.0 \mathrm{E}-1$ & $2.5 E-1$ & 2 \\
\hline 5 & $0 / 0 / 40$ & 0/0/30 & $5.1 \mathrm{E}-1$ & $3.5 \mathrm{E}-1$ & 0 \\
\hline 6 & $10 / 10 / 60$ & 0/0/30 & 3.3E-1 & $3.4 \mathrm{E}-1$ & 0 \\
\hline 7 & $2 / 5 / 30$ & $0 / 0 / 15$ & $2.4 \mathrm{E}+0$ & $1.3 \mathrm{E}+0$ & 0 \\
\hline 8 & $2 / 5 / 30$ & $0 / 0 / 60$ & $3.7 \mathrm{E}-1$ & $6.2 \mathrm{E}-1$ & 0 \\
\hline \multicolumn{3}{|c|}{ Minimum values } & $5.7 \mathrm{E}-2$ & $2.5 \mathrm{E}-1$ & \\
\hline
\end{tabular}

$$
\begin{aligned}
S D_{P} & =\sqrt{\frac{\sum\left(\left(P_{d e v}\right)_{x=i}-\mu_{P d e v}\right)^{2}}{n-1}}, i \\
& =0^{\circ}, 45^{\circ}, \ldots 315^{\circ}, n=8
\end{aligned}
$$

\subsection{Test of CGSI in Plastic Model}

In a similar fashion to the elastic comparison of GSI and CGSI, the calibrated stiffness and strength properties for the joint and vein structures can be applied to an explicit model of the full rockmass containing all rockmass structure, and the plastic depths of yield can be compared to those in corresponding implicit models that use conventional GSI and CGSI (Table 2). The explicit model containing both joints and veins (Fig. 11 right) is the baseline model, where these depths of plastic yield measurements at each $45^{\circ}$ increment around the excavation are subtracted from the same measurements in each of the implicit models to consider the deviation of depth of plastic yield 


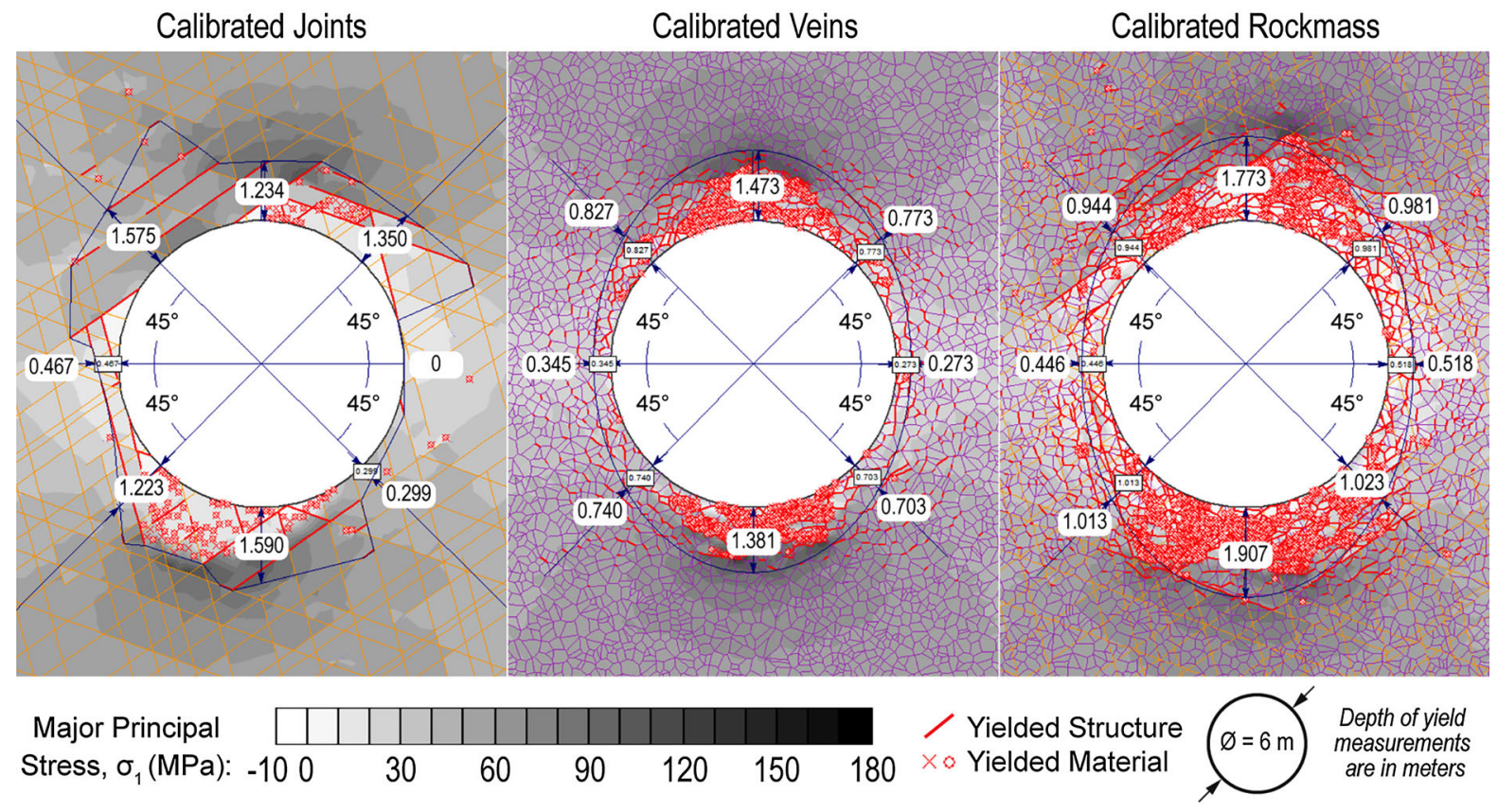

Fig. 11 Calibrated elasto-plastic models showing depth of plastic yield measurements from excavation boundary

(Eq. 13) in the analysis. The best fit implicit model is considered to have the smaller deviation of absolute means of depth of plastic yield (Eq. 14) and the smaller standard deviation of depth of plastic yield (Eq. 15) from the baseline explicit model. The graphical results are shown in Fig. 12 and quantitative results are shown in Table 9.

This analysis shows the Composite GSI (CGSI) implicit rockmass model is an improved fit to the explicit model when compared to the conventional GSI implicit rockmass model results. The result of this elasto-plastic numerical analysis agrees with the result of the elastic analysis.

Overall, the conventional GSI for the rockmass in the implicit models was found to generate larger total displacements and depths of plastic yield in this analysis when compared to the calibrated explicit models. This supports field observations of other complex rockmasses that contain suites of interblock and intrablock structures that suggest the conventional GSI approach underestimates rockmass strength in a complex rockmass where both joints (interblock
Fig. 12 Deviation of depth of plastic yield of implicit equivalent continuum (GSI and CGSI) rockmass models from the baseline model with explicit structure

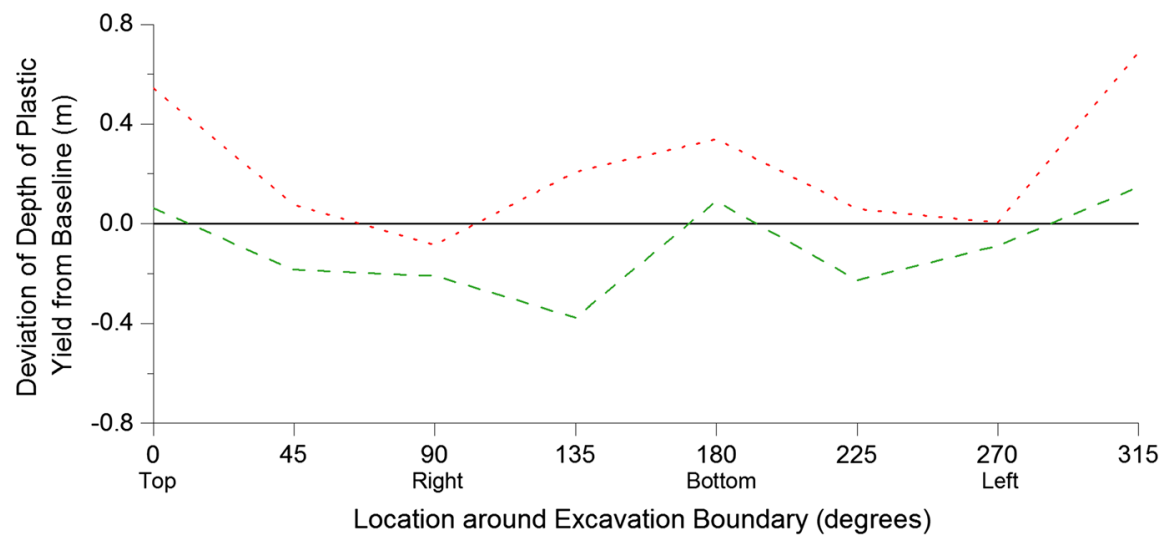

_ Baseline Explicit Rockmass (Joints + Veins) … Implicit Rockmass GSI - - Implicit Rockmass CGS 
Table 9 Quantitative analysis of plastic deviation of depth of plastic yield comparing GSI and CGSI implicit models to baseline explicit model with all rockmass structure

\begin{tabular}{|c|c|c|}
\hline Implicit models & $\begin{array}{c}\text { Absolute } \\
\text { mean }\end{array}$ & Standard deviation \\
\hline GSI & $2.3 \mathrm{E}-1$ & $3.7 \mathrm{E}-1$ \\
\hline CGSI $^{*}$ & $\mathbf{9 . 9 E - 2}$ & $\mathbf{2 . 1 E - 1}$ \\
\hline Minimum values & $\mathbf{9 . 9 E - 2}$ & $\mathbf{2 . 1 E - 1}$ \\
\hline
\end{tabular}

structures) and veins (intrablock structures) are considered. These models also demonstrate that implicit models with CGSI provide an improved representation of total displacements and depth of plastic yield found in explicit models of a tunnel.

\section{Field Case Study Validation of Composite GSI}

In this section, the CGSI method, as applied to rockmass behaviour evaluation using equivalent continuum FEM models, is used to analyze a case study of an adit at the El Teniente porphyry $\mathrm{Cu}-\mathrm{Mo}$ mine in Chile and compare its effectiveness with conventional GSI. The El Teniente mine owned by Codelco is currently the largest underground block caving operation in the world (e.g. Stern et al. 2011). It is located in the Andean Cordillera in central Chile, approximately $70 \mathrm{~km} \mathrm{SSE}$ of the capital city, Santiago. The main lithological units in the deposit include breccia, andesite, diorite, and a stockwork mafic complex. The stockwork intrablock structure is known to affect rockmass behaviour (Brzovic and Villaescusa 2007). The mine has been in operation since the early twentieth century. Higher elevations of the deposit have been completely mined, leaving a large subsidence crater above current production levels. The adit analyzed in this case study was planned to connect from ground surface to the new mine level, up to a depth of approximately $1000 \mathrm{~m}$ below ground surface.

\subsection{Site Observations in El Teniente Mine Adit}

The sections of the adit considered for this study are excavation faces observed at depths of approximately 450, 550, and $600 \mathrm{~m}$, as shown in Fig. 13. The design profile for the adit is an arched roof geometry, approximately $6 \mathrm{~m}$ high and $6 \mathrm{~m}$ wide. All observed excavation faces occur in the stockwork mafic complex geological unit. Several joint sets (interblock structures) were observed in detail at the $600 \mathrm{~m}$ deep face in addition to a stockwork suite of hydrothermal quartz veins (intrablock structure). Annotated photos of the excavation face at $600 \mathrm{~m}$ (Fig. 14) show four joint sets highlighted by blue, green, pink, and yellow polygons. The approximate orientations of the joint planes and adit are shown in a stereonet in Fig. 15. The adit is advancing eastward. The average spacing of the quartz veins is defined by the fragmented block sizes of the excavated material, which are visible in the muck pile at the face in Fig. 14c. Vein spacing controlling the fragmented block size is consistent with field observations by the authors as well as those by Brzovic and Villaescusa (2007). The range of fragmented block sizes is shown in Fig. 16, where a
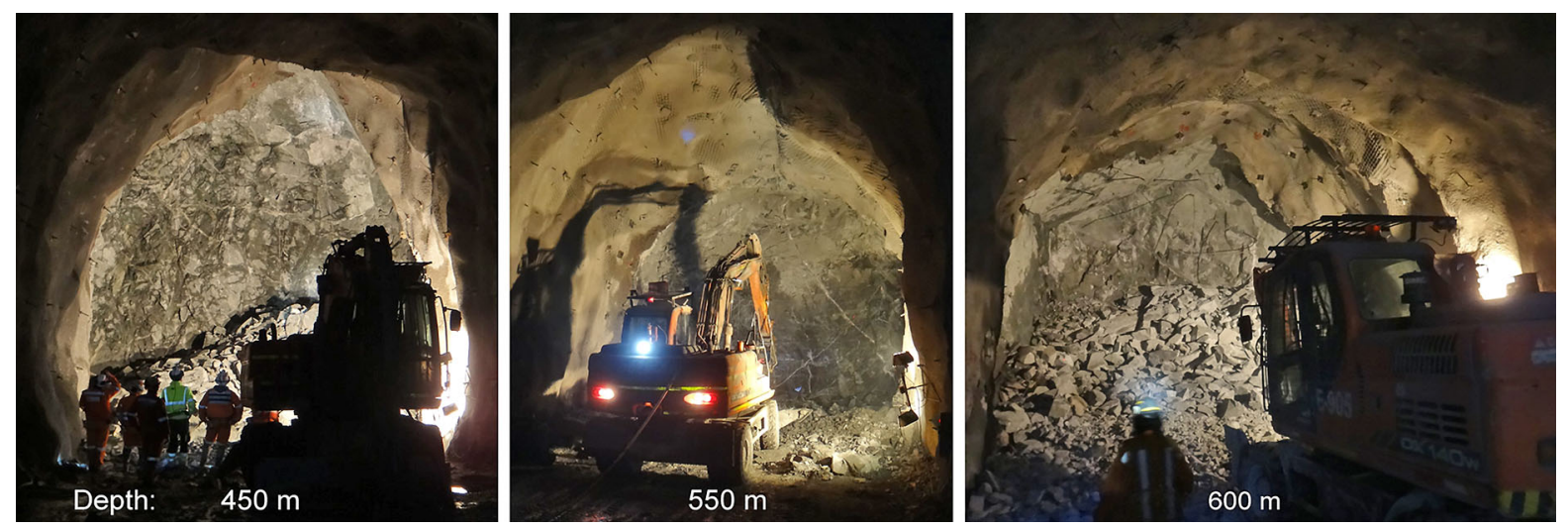

Fig. 13 Excavation faces along the adit at various depths below ground surface 

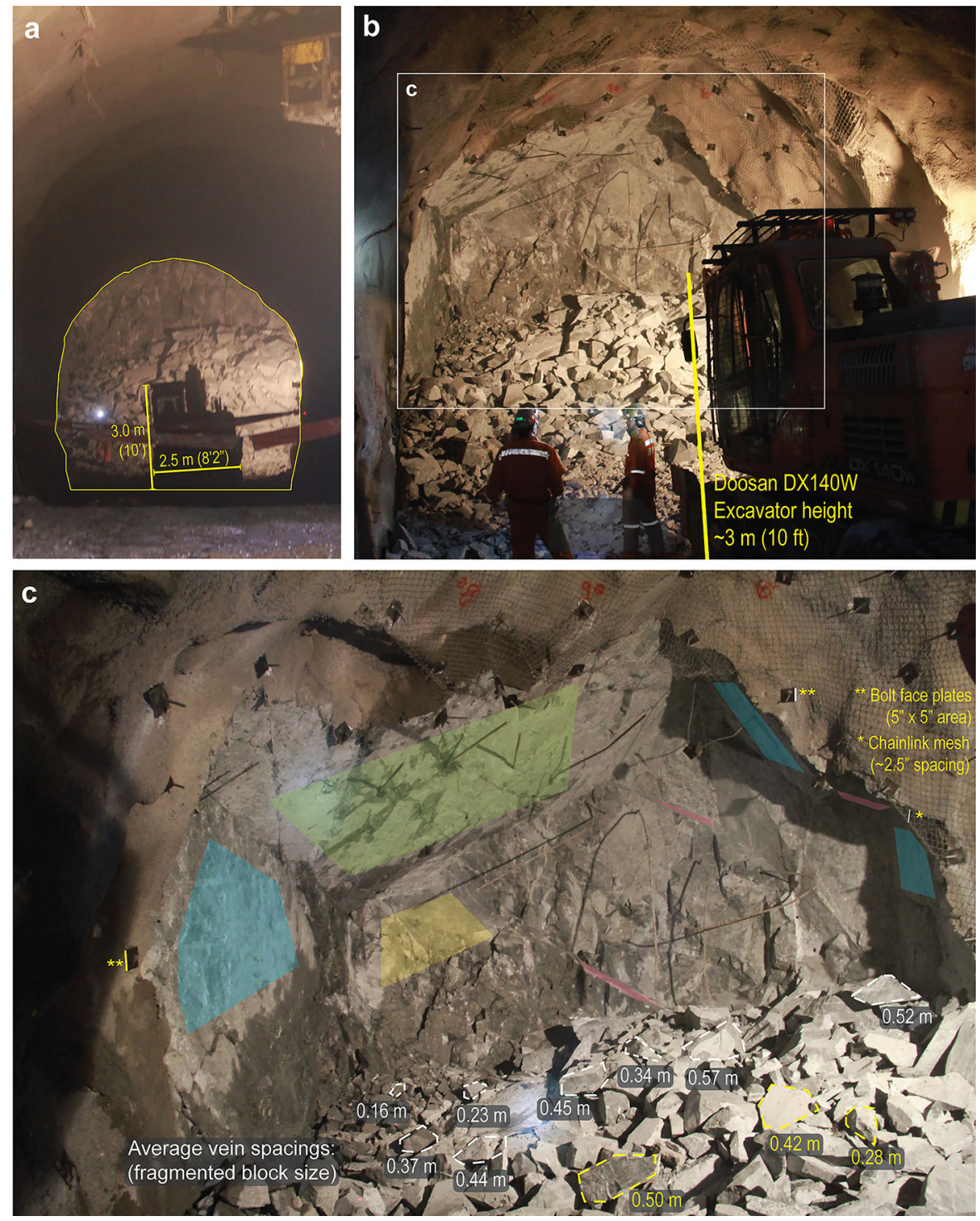

Fig. 14 Site observations from the $600 \mathrm{~m}$ deep excavation face of the adit at El Teniente. a Approximate excavation profile of adit approximately $5 \mathrm{~m}$ behind the face; $\mathbf{b}$ view of excavation face including immediate roof; $\mathbf{b}$ detailed view of excavation

normal distribution is used to calculate an average vein spacing of $0.39 \mathrm{~m}$.

All four joint sets are considered together as a single suite of rockmass structure, with the same surface condition ranked as "very good" quality on the GSI chart. The joint spacing is greater than $1 \mathrm{~m}$, resulting in a "blocky" ranking on the GSI chart. The quartz veins comprise a second suite of structure, ranked as high quality "strengthening intrablock structure" and moderate "very blocky" on the GSI face with highlighted joint planes (4 sets) and average quartz vein spacing defined by the fragmented block size of the excavated material

chart (see Fig. 3). Based on these GSI assessments, Scales A and B (Eqs. 5-8) and corresponding calculated GSI and CGSI values are listed in Table 10.

Ignoring intrablock structure would generate GSI for only joints $(\mathrm{GSI}=80$ ), which is considered to overestimate rockmass strength in this case. Likewise, a conservative conventional approach considers the worst case of the combined suites of structure, GSI $=65$, which is considered to underestimate rockmass strength in this case. These scenarios are 


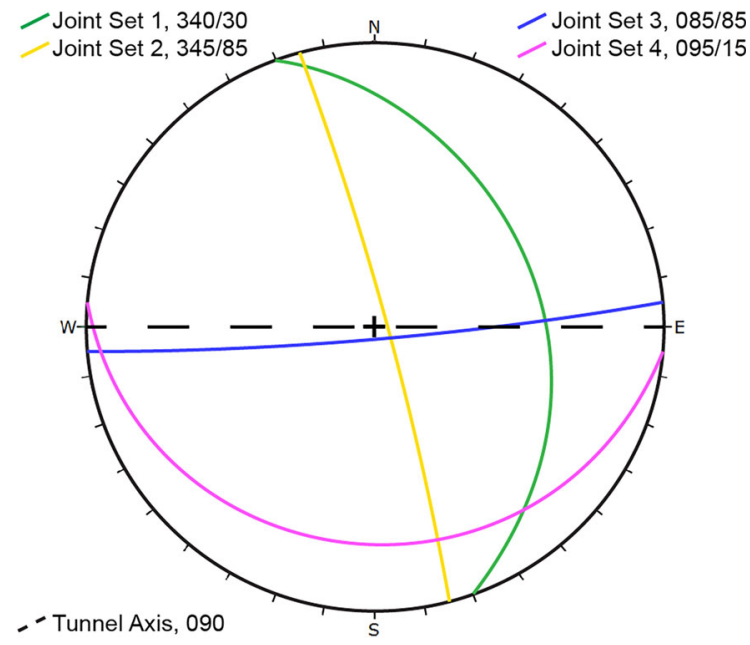

Fig. 15 Stereonet showing observed adit and joint set orientations (right-hand strike/dip)

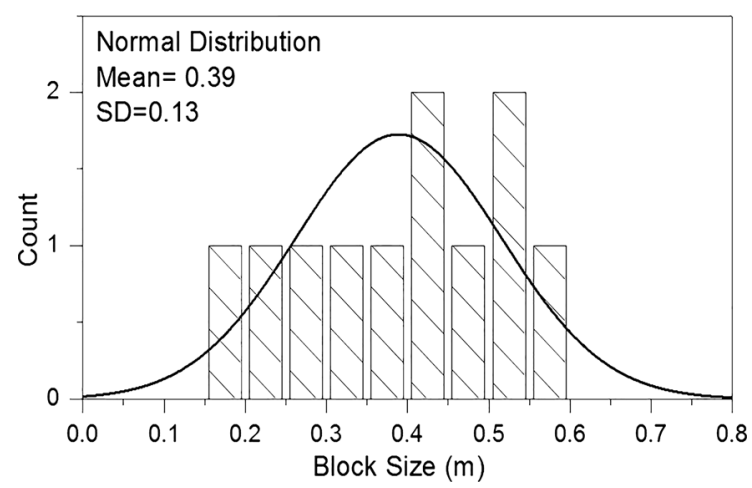

Fig. 16 Histogram of selected block sizes as measurement of average spacing of quartz veins

compared to the CGSI assessment of CGSI $=73$ using FEM models in the following sections.

\subsection{General Numerical Model Setup}

FEM numerical models of the adit were created using RS2 software by RocScience (2015). The adit is assumed to be far enough away from any other excavation such that it is not affected by other induced stresses. In situ stresses have been measured in the mine at various locations using multiple techniques including overcoring and borehole breakout observations, which were analyzed by Diederichs (2016). The minor principal stress $\left(\sigma_{3}\right)$ is oriented vertically while the major $\left(\sigma_{1}\right)$ and intermediate $\left(\sigma_{2}\right)$ principal stresses are oriented horizontally. The $\mathrm{K}$ ratios between $\sigma_{1}$ versus $\sigma_{3}$ and $\sigma_{2}$ versus $\sigma_{3}$ tend to decrease with increasing depth (D) (see Fig. 17). The maximum K ratio relationships are:

$\sigma_{1}=\sigma_{3}\left(1+60 \mathrm{D}^{-0.6}\right)$
$\sigma_{2}=\sigma_{3}\left(1+20 \mathrm{D}^{-0.6}\right)$

An estimated intermediate set of $\mathrm{K}$ ratio relationships was selected for this case study, however, to account for stress rotations caused by mining activities (e.g. McKinnon and Garrido de la Barra 2003), as follows:

$\sigma_{1}=\sigma_{3}\left(1+40 \mathrm{D}^{-0.6}\right)$

$\sigma_{2}=\sigma_{3}\left(1+10 \mathrm{D}^{-0.6}\right)$

The explicit rockmass structure in the models is based on site observations from the $600 \mathrm{~m}$ deep excavation face (Fig. 14). The equivalent continuum region of the explicit models is implemented in the far field sections of the model, away from the adit (see Fig. 18), to alleviate the high computational requirements required for explicit structure. The geometries of the rockmass structure are visible in Fig. 18 (inset) where the joints are modelled with parallel statistical elements and the veins are modelled with Voronoi polygonal elements. Joint set 2 is excluded from these 2D models because its orientation is nearly perpendicular to the excavation (and therefore nearly parallel to the model plane).
Table 10 GSI and CGSI properties of observed rockmass structures

\begin{tabular}{llll}
\hline Structure & Scale A & Scale B & GSI \\
\hline All joint sets combined & 40 & 40 & 80 \\
Hydrothermal veins & 55 & 25 & 80 \\
Conventional worst case GSI & 40 & 25 & 65 \\
CGSI & A $^{*}=49$ & B $^{*}=24$ & CGSI $=73$ \\
\hline
\end{tabular}


Fig. 17 In situ stresses at El Teniente (Diederichs 2016)
In situ Stress

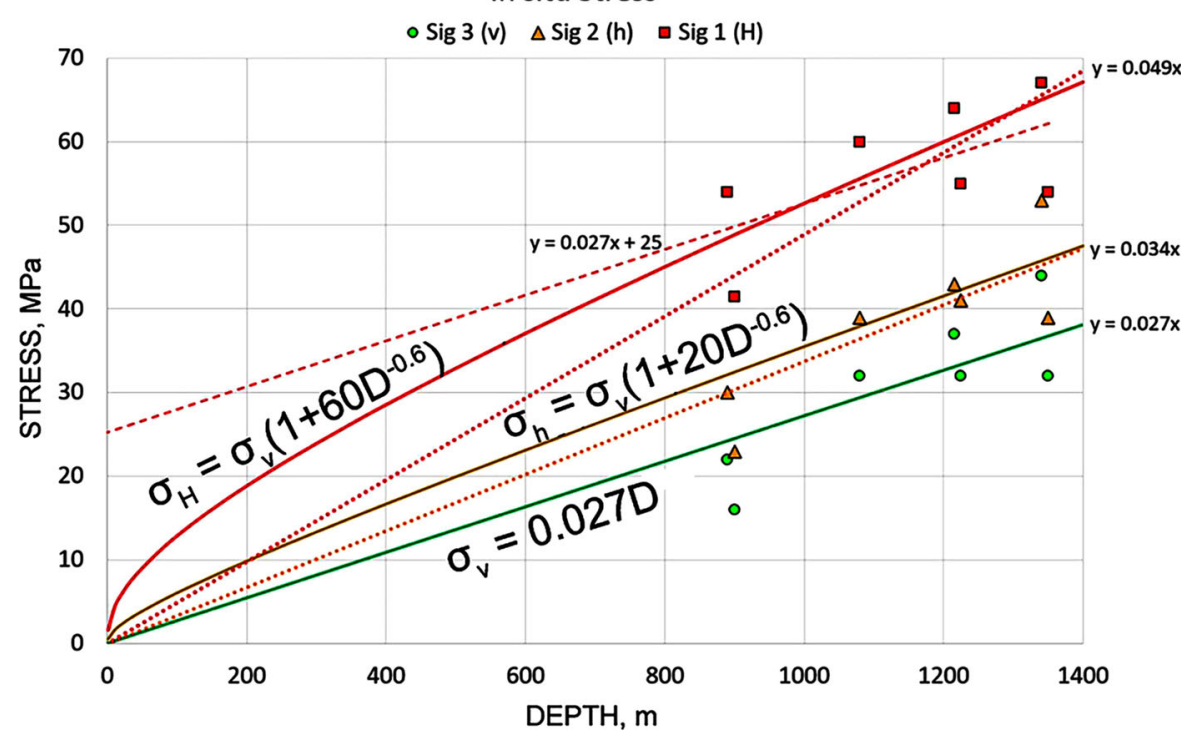

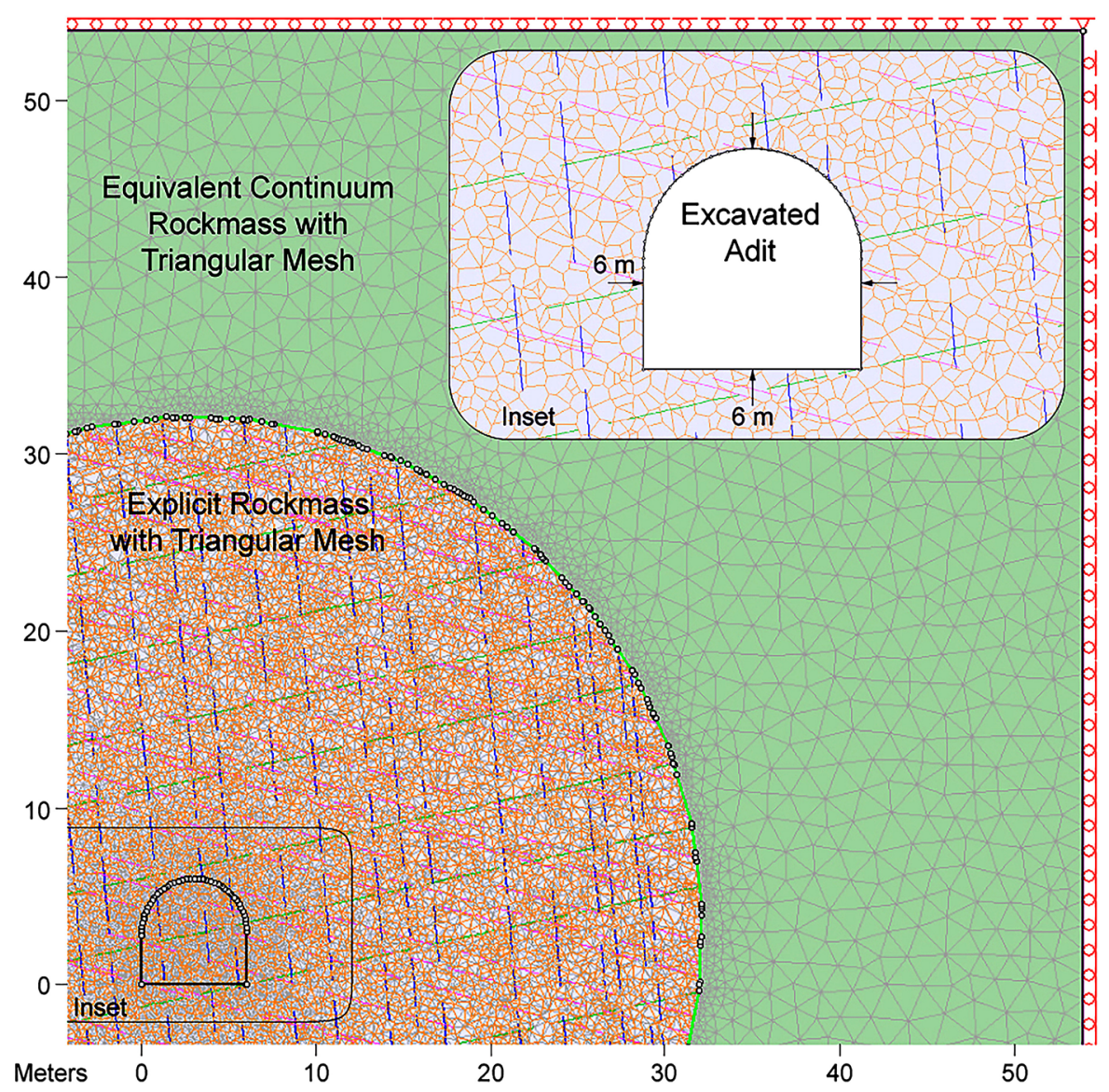

Fig. 18 Relevant quadrant of FEM model with explicit structure, and a detailed inset of explicit structure and adit dimensions 
Table 11 Intact properties of stockwork mafic complex

\begin{tabular}{ll}
\hline Parameter (units) & Value \\
\hline Intact Young's modulus, $\mathrm{E}_{\mathrm{i}}(\mathrm{MPa})$ & 60,000 \\
Poisson's ratio, $v$ & 0.18 \\
Unconfined compressive strength, $\sigma_{\mathrm{ci}}(\mathrm{MPa})$ & 120 \\
Hoek-Brown material constant, $m_{i}$ & 9.1 \\
Hoek-Brown material constant, $s$ & 1 \\
Hoek-Brown material constant, $a$ & 0.5 \\
\hline
\end{tabular}

The intact rock properties of the stockwork mafic complex (Table 11) are from laboratory testing conducted at the mine. The geometry of the modelled rockmass structure is based on site observations (Table 12). The mechanical properties of the joints and veins (Table 13) are based on those reported by Read and Stacey (2009) and Day et al. (2014).

\subsection{Model Analysis Using Depth of Rockmass Yield}

FEM models of the adit with rockmass structure observed at the $600 \mathrm{~m}$ deep face were created using:

i. Explicit rockmass structure,

and three equivalent continuum models with implicit structure represented by:

ii. Joints only (highest GSI) that ignores the presence of intrablock structure,

iii. Composite GSI (CGSI) values, and

iv. Worst-case conventional GSI values.

The models are compared using depth of plastic yield from the excavation boundary, measured at the roof, as an analogue for overbreak. Detailed results are shown in Fig. 19. The yield of both the structural elements and intact rock are considered for the explicit model. Only yielded elements that can be traced to the excavation boundary through other yielded segments
Table 13 Mechanical properties of rockmass structure

\begin{tabular}{lrl}
\hline Parameter (units) & Joints & Quartz veins \\
\hline Normal stiffness, $\mathrm{K}_{\mathrm{n}}(\mathrm{MPa} / \mathrm{m})$ & 30,000 & $6,500,000$ \\
Shear stiffness, $\mathrm{K}_{\mathrm{s}}(\mathrm{MPa} / \mathrm{m})$ & 10,000 & $6,500,000$ \\
Mohr-Coulomb strength criterion & & \\
Peak tensile strength, $\sigma_{\mathrm{t}}(\mathrm{MPa})$ & 0 & 0.1 \\
Peak cohesion, c $(\mathrm{MPa})$ & 1 & 4.3 \\
Peak friction angle, $\phi\left(^{\circ}\right)$ & 55 & 25 \\
Residual tensile strength, $\sigma_{\mathrm{t}}(\mathrm{MPa})$ & 0 & 0 \\
Residual cohesion, c $(\mathrm{MPa})$ & 0 & 0.2 \\
Residual friction angle, $\phi\left(^{\circ}\right)$ & 25 & 40 \\
\hline
\end{tabular}

are included. Single yielded segments surrounded by otherwise intact rock and rockmass structure (typically far from the excavation) are assumed to have insignificant influence on overbreak and are therefore excluded. In the model with explicit structure, most of the yield occurs through the structural elements instead of the intact rock. This is consistent with site observations (Fig. 14) where most failure at the $600 \mathrm{~m}$ face occurred along the joints and veins, and further block fragmentation occurred through the veins.

When comparing the explicit model of the $600 \mathrm{~m}$ deep face to the implicit equivalent continuum models represented by three different GSI approaches, the CGSI model is the best estimate of roof depth of yield (Figs. 19, 20). This finding validates the use of CGSI for continuum modelling of complex rockmasses with intrablock structure at depth.

\subsection{Extension of Analysis to Various Excavation Depths}

The FEM models with rockmass structure based on the $600 \mathrm{~m}$ deep excavation face were modelled at numerous excavation depths between 100 and 2000 m below ground surface to investigate the applicability of the CGSI method for a range of stress conditions. The
Table 12 Geometry of modelled rockmass structure

\begin{tabular}{lllll}
\hline Parameter (units) & Joint set 1 & Joint set 2 & Joint set 3 & Quartz veins \\
\hline Inclination $\left(^{\circ}\right)$ & 12 & -85 & -15 & - \\
Average spacing $(\mathrm{m})$ & 3 & 2.5 & 1 & 0.25 \\
Average length $(\mathrm{m})$ & 4 & 2 & 2 & - \\
Persistence & 0.9 & 0.7 & 0.7 & - \\
Joint end condition & Open & Open & Open & Open \\
Voronoi regularity & - & - & - & Irregular \\
\hline
\end{tabular}


Explicit Structure

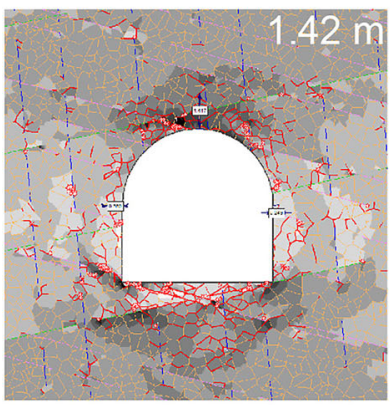

Major Principal Stress, $\sigma_{1}(\mathrm{MPa})$
Joints only GSI
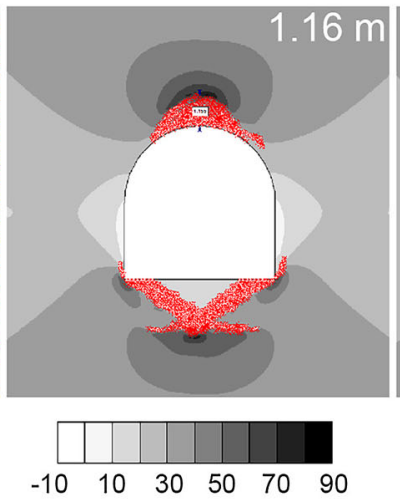

Fig. 19 FEM model results of the $600 \mathrm{~m}$ deep excavation face of the adit at El Teniente, comparing maximum principal stresses $\left(\sigma_{1}\right)$ and yielded elements, for the explicit and GSI

Composite GSI

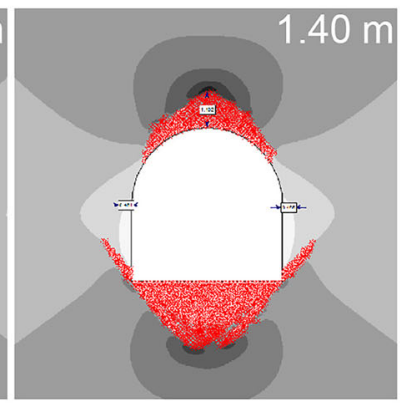

Yielded Structure xo Yielded Material
Worst case GSI

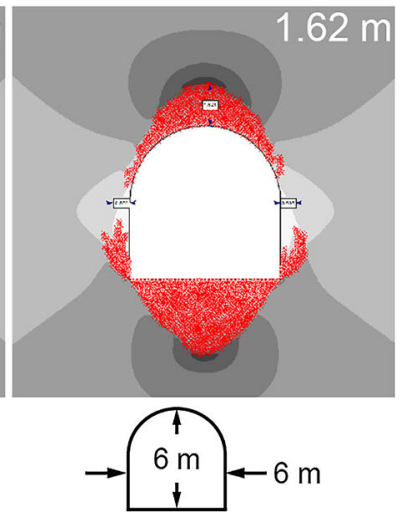

equivalent continuum models; depth of yield measurements in the roof are indicated for each model

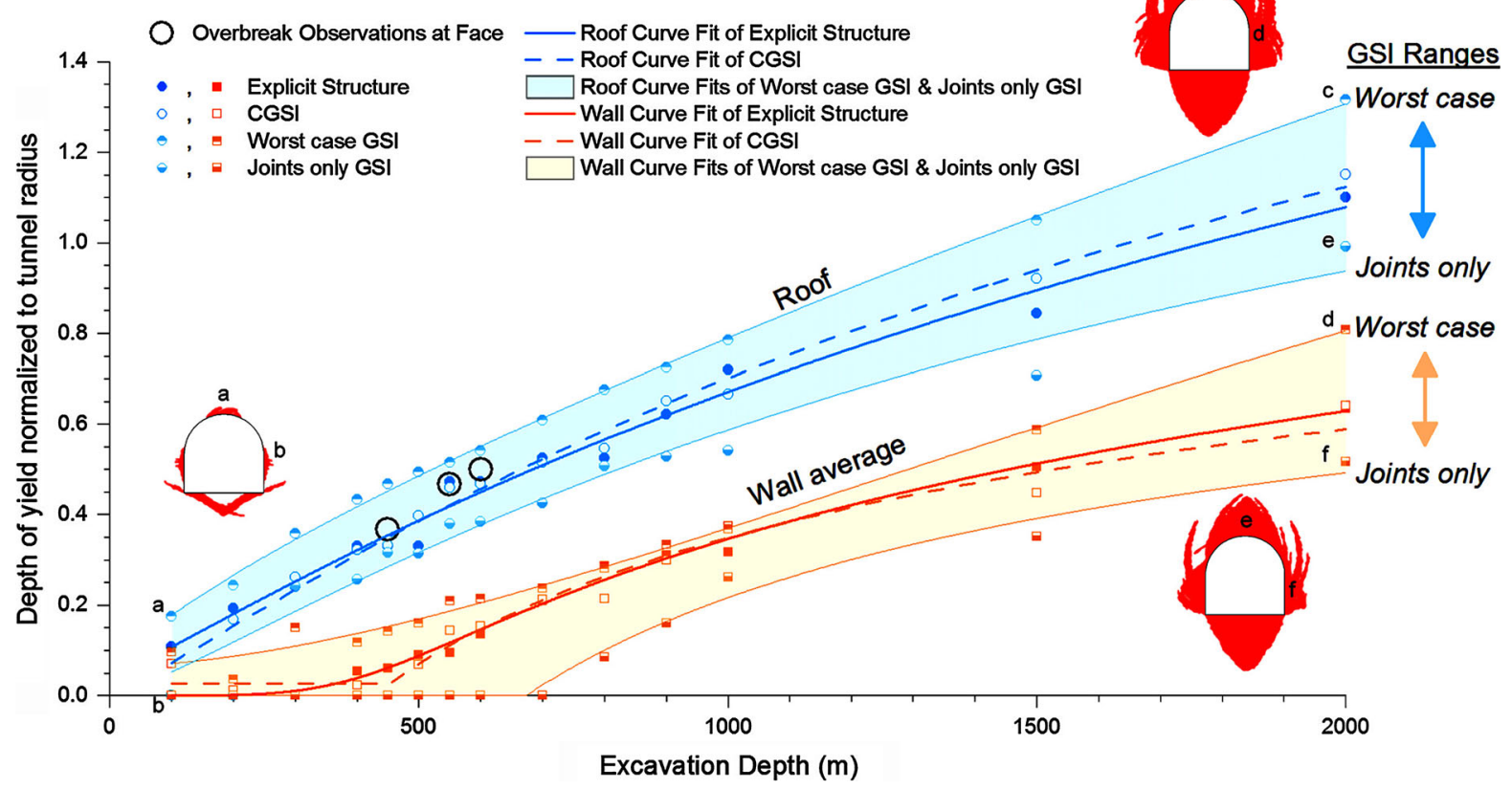

Fig. 20 Estimated depth of yield measurements (normalized to $3 \mathrm{~m}$ tunnel radius) from FEM models at a range of excavation depths show a better fit between the explicit and CGSI solutions when compared to the conventional worst case and joints only GSI approaches. The nonlinear data curves are best fits of the

in situ stress conditions for these models vary according to the stress analysis by Diederichs (2016) (see Fig. 17). The model results for depth of yield measurements are shown in Fig. 20. The nonlinear curve fit selected for these data sets is the Carreau-
Carreau-Yasuda rheological model. The explicit rockmass structure and equivalent continuum GSI values in the FEM models are based on observations at the $600 \mathrm{~m}$ deep adit excavation face

Yasuda model that is designed to describe pseudoplastic flow with asymptotic viscosities at zero and infinite shear rates. The Carreau-Yasuda model enables asymptotic behaviour toward zero depth of yield in shallow conditions. These best-fit functions 
were solved using the Levenberg-Marquardt iteration algorithm.

The overbreak site observations at the 450 and $550 \mathrm{~m}$ excavation faces are plotted in Fig. 20 and, like the $600 \mathrm{~m}$ deep model, their explicit models are in good agreement with the CGSI models. The worstcase conventional GSI approach underestimates the rockmass strength, resulting in a significantly larger depth of yield when compared to the explicit models, CGSI models, and field observations. In contrast, the conventional joints-only GSI that ignores intrablock structure overestimates the rockmass strength, resulting in an underestimated depth of yield. The consequences for both conventional approaches must be considered in the design of primary ground support, where optimized bolt lengths are required to support the rockmass effectively and efficiently. The overbreak observations at excavation faces at 450, 550, and $600 \mathrm{~m}$ depths are best approximated using the CGSI equivalent continuum models.

At the majority of excavation depths greater than $200 \mathrm{~m}$, the CGSI models continue to show the best approximation of the explicit models (in terms of depth of yield). This observation is more consistent in the roof measurements than the walls, which is attributed to an in situ stress ratio of $K>1$ and geometry effects of the arched adit with corners at the floor. The CGSI models deviate from the explicit models in shallow conditions at less than $200 \mathrm{~m}$ depth, which is explained by structurally controlled behaviour at low confinement that cannot be captured by continuum models. Indeed, no GSI approach is intended for use in this scenario.

\section{Discussion}

Geotechnical analysis for underground excavation stability design in complex geological rockmasses requires more rigorous consideration of the impact of intrablock structures such as hydrothermal stockwork vein networks on rockmass behaviour. Intrablock structures occur within blocks of otherwise intact rock bounded by interblock structures, which are the joints and other open fractures conventionally considered in rockmass characterization, classification, and geotechnical rockmass property evaluation. When intersecting with deeper modern excavations, particularly with complex geometries and stress paths, field observations have demonstrated that intrablock structures can have a significant influence on overall rockmass behaviour. This study presents a rockmass characterization methodology and tool to incorporate intrablock structures into numerical geotechnical design practice: a modified GSI chart that includes intrablock structures and the CGSI methodology to combine multiple suites of rockmass structure.

GSI is a more flexible rockmass characterization tool that is directly tied into the Generalized HoekBrown strength criterion, which is available in many modern geotechnical software packages to control the geomechanical behaviour of continuum materials. Application of conventional characterization rationale to complex rockmasses would over-penalize the rockmass by using the worst case strength value of multiple structures; for example, by using the worst case in GSI of the structure and surface condition present. While intrablock structures can dominate the behaviour in a rockmass, they may not weaken the rockmass to that extent and may even strengthen the rockmass with certain infill mineralogies or geometry.

The modified GSI chart presented here is based on the current linearized and quantitative version by Hoek et al. (2013), and the primary modifications are an additional category in the discontinuity surface condition component for strengthening intrablock structures and additions to existing surface condition categories for intrablock structures with a range of competence and strength. Furthermore, a row for massive structure geometry has been reinstated to incorporate widely spaced structures. In particular, this enables strengthening intrablock structures, which may counteract other micro-defects in the rock at the field scale, to result in GSI values between 85 and 100 .

The determinations of weakening and strengthening discontinuity condition are primarily based on the hardness and strength of infill minerals. For instance, hydrothermal quartz veins with a strong welded bond to the wall rock would be among the highest intrablock qualities while weakly bonded, friable calcite or gypsum veins with poor adhesion would be among the lowest qualities. To quantify the discontinuity condition, modifications were made to the Joint Condition rating from RMR by Bieniawski (1989), JCond $_{89}$, to include intrablock structures. Quantification of the rockmass structure geometry in the modified GSI chart for complex rockmasses is based on a logarithmic scale of block volume after Cai et al. 
(2004). This new GSI chart for complex rockmasses can still be used for common jointed blocky rockmasses considered in conventional GSI applications, which contain only interblock structures, using guidelines discussed by Hoek et al. (2013). This provides flexibility for application of the new chart in projects that may encounter variable to zero amounts of intrablock structures in different sections or domains.

A key philosophy of the CGSI method is to first assess individual suites of rockmass structure by their GSI components before combining these values using a weighted harmonic average into a CGSI value that represents the rockmass as a whole. This result can be used as a direct input to numerical models where the rockmass structure is considered implicitly using the Generalized Hoek-Brown strength criterion. Continuum modelling where rockmass structures are considered implicitly through strength criteria such as this is a common preliminary step of numerical geotechnical design that is not computationally demanding and requires fewer input parameters than models with explicit rockmass structures.

Two cases are presented in this paper that demonstrate the improvement of the CGSI approach for continuum (implicit) numerical modelling of complex rockmasses over conventional GSI approaches that either take the worst case of structure and discontinuity condition, or ignore intrablock structures altogether. The first case uses FEM modelling to ultimately compare explicit models of a tunnel in a complex rockmass that contains joints and veins with the implicit equivalent models whose Generalized Hoek-Brown criterion material properties are calculated using CGSI and worst-case conventional GSI. Total displacement measurements of the rockmass materials around the excavation are used to compare the elastic models, and depths of plastic yield around the excavation are used to compare the elasto-plastic models. This is a fully numerical comparison, where the stiffness and strength properties of the explicit rockmass structures were individually calibrated by trial and error (in separate joints-only and veins-only models) to determine the best fit of total displacements and depths of plastic yield in the explicit models to those in the implicit models. The baseline implicit model material properties were based on GSI values for equivalent joints-only and veins-only rockmasses. Once the explicit structure properties were calibrated they could then be combined into the full complex rockmass (containing both joints and veins) in an explicit model to test the final comparison between CGSI and worst-case conventional GSI. In both the elastic and plastic model tests, implicit models using CGSI had the smallest deviation of total displacements and depths of plastic yield, respectively, from the explicit model of the calibrated complex rockmass. Thus, this case shows CGSI provides an improved implicit representation of rockmass behaviour compared to worst-case conventional GSI.

The second case presented in this paper is a validation study of CGSI, compared to conventional GSI, using field observations and data of an adit at the El Teniente mine in Chile and FEM numerical modelling. Model input properties came from field data, the mining company, and literature sources. Field observations at the excavation face in the adit at 450 , 550, and $600 \mathrm{~m}$ depths provided the rockmass structure geometry and excavation profile; the mining company provided intact rock mechanical properties; and literature sources were consulted for in situ stress conditions and discontinuity mechanical properties. Explicit models of the adit and complex rockmass at various depths were compared to equivalent continuum implicit models with Hoek-Brown material properties calculated using CGSI and two conventional GSI values: worst-case GSI and joints-only GSI. In this analysis, the models were compared using the depth of plastic yield in the roof and walls normalized to the tunnel radius, where the best fit implicit model had the smallest deviation from the explicit model.

The FEM results of the CGSI models show better representations of both the explicit numerical models and site observations of excavation faces in the adit at 450, 550, and $600 \mathrm{~m}$ depths. Further FEM models at various depths between 300 and $2000 \mathrm{~m}$ show the CGSI models provide more accurate estimates of yield depth than the conventional worst case and joints only GSI models when compared to the explicit models. The depth of yield for equivalent continuum models at depths of less than $200 \mathrm{~m}$ deviate from the explicit models, which can be explained by structurally driven failure at low confinements that is not appropriate for any continuum modelling method. Overall, this case provides field-based evidence to further validate CGSI for rockmass characterization of complex rockmasses with multiple suites of structure as applied to behaviour evaluation using equivalent continuum FEM numerical models. 


\section{Conclusions}

This study demonstrates the influence of intrablock structures on the mechanical behaviour of complex rockmasses in FEM numerical models, which agrees with observations of rockmass behaviour in deep excavations where intrablock structures can dominate the overall behaviour at the excavation scale. To address the need for field characterization tools of these complex rockmasses, this paper provides a modified GSI chart for complex rockmasses as well as the CGSI method to combine multiple suites of rockmass structure into a weighted harmonic average value. These tools provide a means to include both interblock and intrablock structures in the rockmass characterization process for numerical models of complex rockmasses in geotechnical engineering design. The cases presented in this study also demonstrate that Generalized Hoek-Brown strength criterion properties based on CGSI provide an improved estimation of rockmass behaviour when compared to properties based on conventional GSI approaches.

While success of the proposed characterization tools for complex rockmasses using numerical modelling has been demonstrated in this study using multiple case studies, it is especially important in the field of geomechanics and geotechnical engineering to test these tools in a variety of geological settings to develop an understanding of their strengths and limitations. Furthermore, 2D numerical models were used in this study since the equivalent explicit models in $3 \mathrm{D}$ are currently too computationally demanding for practical use. Therefore, further testing of the concepts and tools in this paper on excavations in a variety of complex rockmasses, as well as in 3D models as computer technology improves, is certainly encouraged.

Acknowledgements The Natural Sciences and Engineering Research Council of Canada, the Centre for Excellence in Mining Innovation, and the Government of Ontario have financially supported this research. The field study components of this research would not have been possible without the generosity and enthusiasm for research of the El Teniente Division of Codelco. Thank you to the anonymous reviewers for their thoughtful and detailed comments, which have certainly improved the quality of this paper.

Open Access This article is distributed under the terms of the Creative Commons Attribution 4.0 International License (http:// creativecommons.org/licenses/by/4.0/), which permits unrestricted use, distribution, and reproduction in any medium, provided you give appropriate credit to the original author(s) and the source, provide a link to the Creative Commons license, and indicate if changes were made.

\section{References}

Babendererde S, Hoek E, Marinos P, Cardoso AS (2004) Characterization of granite and the underground construction in Metro do Porto, Portugal. In: Proceedings of international conference on site characterization, Porto, Portugal, 19-22 September

Bandis S, Lumsden AC, Barton N (1983) Fundamentals of rock joint deformation. Int J Rock Mech Min Sci Geomech Abstr 20(6):249-268. https://doi.org/10.1016/01489062(83)90595-8

Barton N, Lien R, Lunde J (1974) Engineering classification of rock masses for the design of tunnel support. Rock Mech 6(4):189-236. https://doi.org/10.1007/BF01239496

Bieniawski ZT (1976) Rock mass classification in rock engineering. In: Ed. Bieniawski ZT (ed) Proceedings of symposium on exploration for rock engineering, Balkema, Cape Town, vol 1, pp 97-106

Bieniawski ZT (1989) Engineering rock mass classification. Wiley, New York

Brzovic A, Villaescusa E (2007) Rock mass characterization and assessment of block-forming geological discontinuities during caving of primary copper ore at the El Teniente mine, Chile. Int J Rock Mech Min Sci 44:565-583. https:// doi.org/10.1016/j.ijrmms.2006.09.010

Cai M, Kaiser PK, Uno H, Tasaka Y, Minami M (2004) Estimation of rock mass deformation modulus and strength of jointed hard rock masses using the GSI system. Int J Rock Mech Min Sci 41:3-19. https://doi.org/10.1016/S13651609(03)00025-X

Choquette PW, James NP (1990) Limestones-the burial diagenetic environment. In: McIlreath IA, Morrow DW (eds) Diagenesis, Geoscience Canada reprint series 4, St John's, Nfld., Canada : Geological Association of Canada, Dept. of Earth Science, Memorial University of Newfoundland, vol 4, pp 75-111

Day JJ, Diederichs MS, Hutchinson DJ (2014) Component and system deformation properties of complex rockmasses with healed structure. In: 48th U.S. Rock mechanics geomechanics symposium, ARMA, Minneapolis, USA

Day JJ, Diederichs MS, Hutchinson DJ (2017a) New direct shear testing protocols and analyses for fractures and healed intrablock rockmass discontinuities. Eng Geol 229:53-72. https://doi.org/10.1016/j.enggeo.2017.08.027

Day JJ, Diederichs MS, Hutchinson DJ (2017b) The influence of mineralogy and grain scale features in healed intrablock rockmass structure on direct shear properties in the Cobourg limestone. In: 51st U.S. Rock mechanics geomechanics symposium, ARMA, Minneapolis, USA

Deere DU, Merritt AH, Coon RF (1969) Engineering classification of in situ rock. Technical Report No. AFWL-TR-67144, Kirtland Air Force Base, N.M 
Diederichs MS (2007) The 2003 Canadian Geotechnical Colloquium: mechanistic interpretation and practical application of damage and spalling prediction criteria for deep tunnelling. Can Geotech J 44:1082-1116. https://doi.org/ 10.1139/T07-033

Diederichs MS (2016) Tunnels in the Andes: trials and tribulations. In: Tunnelling association of Canada conference, Ottawa, ON, Canada

Goodman RE (1969) Effect of joints on the strength of tunnels: research on rock bolt reinforcement. Technical Report No. 5, Omaha District, Corps of Engineers: Contract \# DACA45-67-C-0015

Hoek E (1994) Strength of rock and rock mases. ISRM News J 2(2):4-16

Hoek E, Brown ET (1980) Underground excavations in rock. Institution of Mining and Metallurgy, London

Hoek E, Brown ET (1988) The Hoek-Brown failure criteriona 1988 update. In: Curran JC (ed) Proceedings of 15th Canadian rock mechanics symposium on rock engineering for underground excavations. Dept. Civil Eng., University of Toronto, Toronto, pp 31-38

Hoek E, Brown ET (1997) Practical estimates of rock mass strength. Int J Rock Mech Min Sci 34(8):1165-1186. https://doi.org/10.1016/S1365-1609(97)80069-X

Hoek E, Marinos P (2000) Predicting tunnel squeezing problems in weak heterogeneous rock masses. Tunnels and Tunnelling International. Part 1-November 2000, part 2December 2000

Hoek E, Kaiser PK, Bawden WF (1995) Support of underground excavations in hard rock. Balkema, Rotterdam

Hoek E, Carranza-Torres CT, Corkum B (2002) Hoek-Brown failure criterion-2002 edition. In: Proceedings of 5th North American rock mechanics symposium, Toronto, Canada, vol 1, pp 267-273

Hoek E, Carter T, Diederichs MS (2013) Quantification of the Geological Strength Index chart. In: Proceedings of 47th U.S. Rock mechanics symposium. ARMA, San Francisco, USA

Johnson MD, Armstrong DK, Sanford BV, Telford PG, Rutka MA (1992) Paleozoic and mesozoic geology of Ontario. In: Thurston PC, Williams HR, Sutcliffe RH, Stott GM (eds) Geology of Ontario. Special Volume 4, Part 2, Toronto, Ontario Geological Survey, pp 907-1010

Laubscher DH (1977) Geomechanics classification of jointed rock masses-mining applications. Trans Inst Min Metall, Sect A 86:A1-A8

Laubscher DH (1990) A geomechanics classification system for the rating of rock mass in mine design. J S Afr Inst Min Metall 90(10):257-273

Laubscher DH, Jakubec J (2001) Chapter 57: The MRMR rock mass classification for jointed rock masses. In: Hustrulid WA, Bullock RL (eds) Underground mining methods: engineering fundamentals and international case studies. Society for Mining Metallurgy and Exploration, Englewood, pp 475-481

Marinos V (2019) A revised, geotechnical classification GSI system for tectonically disturbed heterogeneous rock masses, such as flysch. Bull Eng Geol Environ
78(2):899-912. https://doi.org/10.1007/s10064-017-1151$\mathrm{Z}$

Marinos V, Carter TG (2018) Maintaining geological reality in application of GSI for design of engineering structures in rock. Eng Geol 239:282-297. https://doi.org/10.1016/j. enggeo.2018.03.022

Marinos P, Hoek E (2001) Estimating the geotechnical properties of heterogeneous rock masses such as Flysch. Bull Eng Geol Environ 60:85-92. https://doi.org/10.1007/ s100640000090

Marinos P, Hoek E, Marinos V (2006) Variability of the engineering properties of rock masses quantified by the geological strength index: the case of ophiolites with special emphasis on tunnelling. Bull Eng Geol Environ 65:129-142. https://doi.org/10.1007/s10064-005-0018-x

Martin CD (1997) Seventeenth Canadian geotechnical colloquium: the effect of cohesion loss and stress path on brittle rock strength. Can Geotech J 34:698-725

McKinnon SD, Garrido de la Barra I (2003) Stress field analysis at the El Teniente Mine: evidence for $\mathrm{N}-\mathrm{S}$ compression in the modern Andes. J Struct Geol 25:2125-2139. https:// doi.org/10.1016/S0191-8141(03)00068-3

Mohs F (1825) Treatise on mineralogy. Translated by Haidinger W. Caledonian Mercury Press, Edinburgh

Palmstrøm A (1996) Characterizing rock masses by the RMi for use in practical rock engineering; part 1: the development of the Rock Mass index (RMi). Tunn Undergr Space Technol 11(2):175-188. https://doi.org/10.1016/08867798(96)00015-6

Read J, Stacey P (2009) Guidelines for open pit slope design. CSIRO Publishing, Clayton

RocScience Inc. (2015) RS2-Phase ${ }^{2}$ Version 9.01064 bit. www.RocScience.com. Toronto, ON, Canada

Sinclair WD (2007) Porphyry deposits. In: Goodfellow WD (ed) Mineral deposits of Canada: a synthesis of major deposittypes, district metallogeny, the evolution of geological provinces, and exploration methods. GAC, Mineral Deposits Division, Special Publication No. 5, pp 223-243

Sonmez H, Ulusay R (1999) Modifications to the geological strength index (GSI) and their applicability to stability of slopes. Int J Rock Mech Min Sci 36:743-760. https://doi. org/10.1016/S0148-9062(99)00043-1

Stern CR, Skewes MA, Arévalo A (2011) Magmatic evolution of the giant El Teniente $\mathrm{Cu}-\mathrm{Mo}$ deposit, central Chile. J Petrol 52(7\&8):1591-1617. https://doi.org/10.1093/ petrology/egq029

Tabor D (1954) Mohs's hardness scale—a physical interpretation. Proc Phys Soc B 67:249-257

van der Pouw Kraan M (2014) Rockmass behavioural uncertainty: implications for hard rock tunnel geotechnical baseline reports. MASc Thesis, Dept. of Geological Sciences and Geological Engineering, Queen's University, Kingston, ON, Canada

Publisher's Note Springer Nature remains neutral with regard to jurisdictional claims in published maps and institutional affiliations. 